\title{
AVALIAÇÃO DE DIFERENTES CULTURAS STARTERS NA ELABORAÇÃO DE SALAME TIPO ITALIANO
}

\section{EVALUATION OF DIFFERENT STARTERS CULTURES IN THE OBTAITION OF ITALIAN-TYPE SAUSAGE}

\author{
Elizandro Vedovatto ${ }^{1}$ ORCID http://orcid.org/0000-0002-9003-9747 \\ Clarice Steffens ${ }^{1^{*}}$ ORCID http://orcid.org/0000-0003-4394-125X \\ Rogerio Luis Cansian ${ }^{1}$ ORCID http://orcid.org/0000-0002-1857-9036 \\ Geciane Toniazzo Backes ${ }^{1}$ ORCID http://orcid.org/0000-0001-8652-8399 \\ Roberto Verlindo1 ORCID http://orcid.org/0000-0002-1977-7210
}

${ }^{1}$ Universidade Regional Integrada do Alto Uruguai e das Missões, Erechim, RS, Brasil.

*Autora para correspondência - clarices@uricer.edu.br

\section{Resumo}

O Salame Tipo Italiano produzido no Brasil é predominantemente obtido de carne suína, com maturação aproximada de 30 dias, atingindo $\mathrm{pH}$ em torno de 5,4. O uso das bactérias do gênero Lactobacillus como culturas iniciadoras propicia o processo de fermentação e a obtenção de produtos uniformes e seguros, com redução do tempo de maturação devido à rápida formação de ácido lático, obtendo-se melhores características sensoriais, químicas e microbiológicas. Os estafilococos coagulase-negativos (comumente em produtos cárneos fermentados Staphylococcus xylosus e S. carnosus) possuem vantagens tecnológicas, como atividade de nitrito e nitrato redutase, consumo de oxigênio e atividade de catalase que melhoram a estabilidade de cor e diminuem o desenvolvimento de rancidez no produto, além de contribuírem para a geração de sabor devido à capacidade proteolítica e lipolítica. Portanto, este trabalho objetivou estudar a influência de diferentes culturas starters $(S$. xylosus, S. carnosus, L. sakei e L. plantarum) combinadas com diferentes concentrações de substrato de glicose $(40,5$ e 99,5\%) na fabricação do Salame Tipo Italiano, bem como a influência da concentração destes no desempenho das culturas starters. Durante o processamento e shelf life, os salames foram avaliados quanto às características físico-químicas, microbiológicas e sensoriais. Em todas as amostras de Salame Tipo Italiano houve comportamento similar em relação aos parâmetros físico-químicos (umidade, proteína e gordura). Não houve crescimento de micro-organismos indesejáveis nas amostras analisadas após 60 dias de shelf life. Na análise sensorial, a amostra com menor concentração de substrato (40,5\%), utilizando as culturas $S$. carnosus e $L$. sakei, foi a que recebeu as melhores notas e melhor aceitação pelos degustadores, além de apresentar valores de nitritos e nitratos de acordo com a legislação.

Palavras-chave: Características tecnológicas. Staphylococcus xylosus. Staphylococcus carnosus. Lactobacillus sakei. Lactobacillus plantarum. Substrato de glicose.

\footnotetext{
Abstract

The Italian-Type Sausage produced in Brazil is predominantly obtained from swine meat, with
} 
maturation approximately 30 days, reaching $\mathrm{pH}$ around 5.3. The use of Lactobacillus bacteria as starter cultures provide fermentation processes and products more uniform and safe, reducing the maturation time due to the rapid formation of lactic acid, obtaining products with better sensorial, chemical and microbiological characteristics. Coagulase-negative staphylococci (commonly in $S$. xylosus and S. carnosus fermented meat products) have technological advantages such as nitrite and nitrate redutase activity, oxygen uptake and catalase activity that improve color stability and decrease the development of rancidity in the skin, contribute to the generation of flavor due to the proteolytic and lipolytic capacity. This work aimed to study the influence of different starters cultures (S. xylosus, S. carnosus, L. sakei and L. plantarum) combined with different concentrations of glucose substrate (40.5 and 99.5\%) in properties of Italian-Type Sausage, as well as the influence of their concentration on starter performance. During the processing and shelf life the sausages were evaluated in relation to physic-chemical, microbiological and sensorial characteristics. In all samples of Italian-type Sausages have similar behavior in relation to physical-chemical parameters (moisture, protein, and fat). There was no growth of undesirable micro-organisms in the samples after 60 days of shelf life. By the sensorial analysis, the sample with low concentration of substrate $(40.5 \%)$ and with $S$. carnosus and L. sakei cultures was the one that received the best grades and better acceptance by the tasters, and presented values of nitrites and nitrites according to the legislation.

Keywords: Staphylococcus xylosus. Staphylococcus carnosus. Lactobacillus sakei. Lactobacillus plantarum. Glucose substrate.

Recebido em 28 de agosto de 2017.

Aceito em 27 de junho de 2019.

\section{Introdução}

Devido ao seu elevado valor nutricional, a carne torna-se altamente sensível ao desenvolvimento de micro-organismos que conduzem à sua deterioração. Além disso, a elevada quantidade de água livre e o $\mathrm{pH}$ favorável facilitam o crescimento de micro-organismos indesejáveis. Dessa forma, métodos de conservação que visem ao aumento do shelf life são requeridos. Dentre os processos tradicionais de preservação da carne, destacam-se a salga, secagem e fermentação ${ }^{(1)}$. No passado, a fermentação era o resultado espontâneo da microbiota natural da carne e do ambiente. Entretanto, a fermentação somente pela microbiota natural pode resultar em produtos de qualidade inferior ou mesmo inseguros para o consumo ${ }^{(2)}$. As culturas de micro-organismos, puras ou mistas, chamadas culturas starters, são aquelas disponíveis comercialmente, especialmente nas formas congelada ou liofilizada, que são selecionadas de acordo com a finalidade do uso. Quando adicionadas em produtos fermentados, permitem uma maior uniformidade, reduzem o tempo de fermentação, aumentam o tempo de conservação $^{(3)}$ e conferem características sensoriais desejáveis.

A fermentação é considerada como a etapa mais importante do processamento do salame, nela ocorre a produção de ácido láctico e o consequente abaixamento do $\mathrm{pH}$ do produto $(5,8 \text { a } 5,4)^{(4-5)}$, sendo influenciada pelas características da matéria-prima e do processamento. Entretanto, a acidificação excessiva frequentemente está relacionada com defeitos de coloração e, às vezes, com a formação de gás, sendo um dos importantes problemas de salames fermentados ${ }^{(6)}$. 
A maturação do salame é de aproximadamente trinta dias, em que se obtém aroma e sabor suaves, $\mathrm{pH}$ em torno de 5,4, e atividade de água inferior a 0,87 . A redução da atividade de água caracteriza o final do processo de maturação. Sua fabricação se dá em duas fases: na primeira, há a fermentação com a ocorrência simultânea de acidificação e formação da cor; a segunda fase é a maturação e consiste na desidratação como decorrência da fermentação $0^{(7)}$.

A estabilidade microbiológica do salame se deve principalmente ao seu baixo $\mathrm{pH}$ (abaixo de 5,3 ) e baixo teor de umidade com atividade de água inferior a $0,92^{(5,7)}$.

Várias culturas bacterianas têm sido estudadas para reduzir o tempo de fermentação, assegurando baixo residual no conteúdo de nitrato e nitrito e estabilizando as características sensoriais do produto final ${ }^{(8-9)}$. O açúcar é o principal ingrediente adicionado e serve como fonte de carboidratos para culturas starters. A queda de $\mathrm{pH}$ no salame depende da quantidade de açúcar utilizado, uma vez que a maior quantidade desse açúcar geralmente leva a um menor $\mathrm{pH}$ e acidificação mais acentuada. $\mathrm{O}$ açúcar associado à temperatura de fermentação determina a taxa de formação de ácido lático e, deste modo, aumenta o potencial de crescimento de micro-organismos importantes para o desenvolvimento do sabor, $\mathrm{pH}$ e acidez ${ }^{(1,10)}$.

Devido à necessidade de avaliar o comportamento entre culturas e substratos, este trabalho objetivou estudar a influência de diferentes culturas starters (Staphylococcus xylosus, Staphylococcus carnosus, Lactobacillus sakei e Lactobacillus plantarum) combinada com diferentes concentrações de substrato de glicose (40,5 e 99,5\%), na fabricação do Salame Tipo Italiano na composição físico-química, microbiológica, e nas características sensoriais durante o período de defumação, maturação e shelf life.

\section{Material e Métodos}

Neste estudo, diferentes concentrações de substrato de glicose e cinco culturas starters foram empregadas em formulações de Salame Tipo Italiano semicurado de carne suína, produzido em escala industrial em um abatedouro de grande porte do sul do Brasil, com inspeção pelo CIF. A glicose desidratada (MOR - REX), com concentração de 40,5\%, foi adquirida da empresa Corn Products; e a com concentração de 99,5\%, da empresa Ingredion. Todas as culturas estudadas foram escolhidas por suas atividades tecnológicas já citadas, sendo que foram adquiridas comercialmente (SACCO, e Christian \& Hansen). As formulações foram realizadas combinando cada cultura com duas concentrações de substrato de glicose $(40,5 \%$ e $99,5 \%)$, em que a menor concentração foi representada pela letra $\mathrm{G}$ e a maior por $\mathrm{D}$, totalizando 10 tipos diferentes de ações microbiológicas. A partir disso, as culturas starters e a contagem de bactérias estão demonstradas na Tabela 1, bem como o nome dado a cada formulação do salame.

Para a elaboração do Salame Tipo Italiano, utilizou-se $450 \mathrm{~kg}$ de carne suína e toucinho e 18,74 kg de ingredientes, considerando as concentrações de substrato de glicose (40,5\% e 99,5\%) e as culturas starters. A temperatura da massa pronta ficou entre 6 e $7{ }^{\circ} \mathrm{C}$, sendo embutida em tripas artificiais calibre $70 \mathrm{~mm}$. Posteriormente, foram avaliadas as características do salame nas etapas de defumação, maturação e shelf life (tempo de validade ou vida útil do produto). A defumação foi realizada durante 
30h, a maturação por 28 dias e o shelf life por 60 dias.

Tabela 1: Culturas starters e concentrações de substrato de glicose utilizadas para as formulações do Salame Tipo Italiano

\begin{tabular}{|c|c|c|c|c|}
\hline Formulação & & Culturas starters & & Substrato (\%) \\
\hline GBR1 & $\begin{array}{c}\text { S. xylosus } \\
\left(7,5 \times 10^{6} \mathrm{UFC} / \mathrm{g}\right)\end{array}$ & $\begin{array}{c}\text { S. carnosus } \\
\left(7,5 \times 10^{6} \mathrm{UFC} / \mathrm{g}\right)\end{array}$ & $\begin{array}{c}\text { L. sakei } \\
\left(6,0 \times 10^{6} \mathrm{UFC} / \mathrm{g}\right)\end{array}$ & 40,5 \\
\hline GBR2 & $\begin{array}{c}\text { S. carnosus } \\
\left(1,5 \times 10^{7} \mathrm{UFC} / \mathrm{g}\right)\end{array}$ & $\begin{array}{c}\text { L. sakei } \\
\left(6,0 \times 10^{6} \mathrm{UFC} / \mathrm{g}\right)\end{array}$ & - & 40,5 \\
\hline GBR3 & $\begin{array}{c}\text { S. xylosus } \\
\left(1,5 \times 10^{7} \mathrm{UFC} / \mathrm{g}\right)\end{array}$ & $\begin{array}{c}\text { L. sakei } \\
\left(6,0 \times 10^{6} \mathrm{UFC} / \mathrm{g}\right)\end{array}$ & - & 40,5 \\
\hline GBR4 & $\begin{array}{c}\text { S. carnosus } \\
\left(1,5 \times 10^{7} \mathrm{UFC} / \mathrm{g}\right)\end{array}$ & $\begin{array}{c}\text { L. plantarum } \\
\left(6,0 \times 10^{6} \mathrm{UFC} / \mathrm{g}\right)\end{array}$ & - & 40,5 \\
\hline GBR5 & $\begin{array}{c}\text { S. carnosus } \\
\left(5,55 \times 10^{6} \mathrm{UFC} / \mathrm{g}\right)\end{array}$ & $\begin{array}{c}\text { L.sakei ( } \\
\left.5,55 \times 10^{6} \mathrm{UFC} / \mathrm{g}\right)\end{array}$ & - & 40,5 \\
\hline DBR1 & $\begin{array}{c}\text { S. xylosus } \\
\left(7,5 \times 10^{6} \mathrm{UFC} / \mathrm{g}\right)\end{array}$ & $\begin{array}{c}\text { S. carnosus } \\
\left(7,5 \times 10^{6} \mathrm{UFC} / \mathrm{g}\right)\end{array}$ & $\begin{array}{c}\text { L. sakei } \\
\left(6,0 \times 10^{6} \mathrm{UFC} / \mathrm{g}\right)\end{array}$ & 99,5 \\
\hline DBR2 & $\begin{array}{c}\text { S. carnosus } \\
\left(1,5 \times 10^{7} \mathrm{UFC} / \mathrm{g}\right)\end{array}$ & $\begin{array}{c}\text { L. sakei } \\
\left(6,0 \times 10^{6} \mathrm{UFC} / \mathrm{g}\right)\end{array}$ & - & 99,5 \\
\hline DBR3 & $\begin{array}{c}\text { S. xylosus } \\
\left(1,5 \times 10^{7} \mathrm{UFC} / \mathrm{g}\right)\end{array}$ & $\begin{array}{c}\text { L. sakei } \\
\left(6,0 \times 10^{6} \mathrm{UFC} / \mathrm{g}\right)\end{array}$ & - & 99,5 \\
\hline DBR4 & $\begin{array}{c}\text { S. carnosus } \\
\left(1,5 \times 10^{7} \mathrm{UFC} / \mathrm{g}\right)\end{array}$ & $\begin{array}{l}\text { L. plantarum } \\
\left(6,0 \times 10^{6} \mathrm{UFC} / \mathrm{g}\right)\end{array}$ & - & 99,5 \\
\hline DBR5 & $\begin{array}{c}\text { S. carnosus } \\
\left(5,55 \times 10^{6} \mathrm{UFC} / \mathrm{g}\right)\end{array}$ & $\begin{array}{c}\text { L. sakei } \\
\left(5,55 \times 10^{6} \mathrm{UFC} / \mathrm{g}\right)\end{array}$ & - & 99,5 \\
\hline
\end{tabular}

Fonte: Elaboração própria.

As formulações foram enviadas para um fumeiro, no qual o processo de defumação iniciou após $3 \mathrm{~h}$ da elaboração do salame. Os fumeiros tinham operação manual, e a fumaça (proveniente da queima da madeira) foi inserida no fumeiro com objetivo de aumentar a temperatura do produto para iniciar a fermentação e conferir o sabor característico.

Nesse fumeiro, as amostras foram colocadas na mesma posição horizontal para garantir homogeneidade de temperatura e umidade. A temperatura e umidade na entrada e na saída do fumeiro foram monitoradas por dataloggers (AK285 - 8835 - AKSO). O fumeiro operou em condições normais de produção comercial, com temperatura de $25-35^{\circ} \mathrm{C}$ e umidade de $60-80 \%$, a defumação foi realizada durante $30 \mathrm{~h}$. A temperatura interna do produto se manteve entre 25 a $30{ }^{\circ} \mathrm{C}$, a qual foi monitorada com o auxílio de um datalogger.

$\mathrm{Na}$ etapa de maturação (28 dias), as amostras foram colocadas em salas de cura (Maurer) na posição horizontal para garantir as condições de temperatura, umidade e fluxo de ventilação, sendo monitoradas com os dataloggers (AK285-8835-AKSO) em posições de frente e fundo da sala. Quando o produto atingiu valor de atividade de água abaixo de 0,90, ele foi embalado a vácuo, em embalagem termoencolhível com alta barreira ao oxigênio (Taxa de Permeabilidade ao $\mathrm{O}_{2}<10 \mathrm{~cm}^{3} / \mathrm{m}^{2}$ dia).

Durante o período de shelf life (60 dias de armazenamento), as amostras permaneceram em local seco e fresco a $22{ }^{\circ} \mathrm{C}$, embaladas a vácuo, dentro de caixas secundárias de papelão, evitando, com isso, 
exposição a oxigênio e luminosidade.

As análises físico-químicas foram realizadas nas três etapas do processo (defumação, maturação e shelf life), sendo avaliado o pH (pHmetro DM 22 - Digimed) e a atividade de água (Aw) (Medidor de Atividade de Água - AquaLab, series, 3TE). Os teores de nitrito e nitrato, umidade, proteína e gordura foram avaliados de acordo com as normas da $\mathrm{AOAC}^{(11)}$. Os parâmetros físicos analisados foram: dureza, adesividade, elasticidade, coesividade e mastigabilidade por meio do equipamento texturômetro (TA XT - Stable Micro Systems Ltda). Todas as análises foram realizadas em triplicata.

Nos salames após 60 dias de shelf life, foram realizadas as análises microbiológicas de Listeria monocytogenes $(\mathrm{LMO}-\mathrm{ALIM})^{(12)}$, Salmonella sp. $(\mathrm{MDS}-\mathrm{SLM})^{(13)}$, Coliformes Termotolerantes $\left(\right.$ PETRI - CC) ${ }^{(14)}$ e Staphylococcus coagulase positiva (PETRI - STX) ${ }^{(15)}$. Também foram realizadas análises de bactérias láticas durante as etapas de defumação, maturação e shelf life, segundo $\mathrm{APHA}^{(16)}$.

A análise sensorial foi realizada com uma equipe treinada composta por 15 julgadores, de ambos os sexos, apresentando idades entre 18 e 50 anos. Os treinamentos dos atributos no ponto fraco da escala foram para odor, sabor, cor, textura, acidez e amargor. A intensidade de cada um deles foi avaliada através de uma escala não estruturada de $9 \mathrm{~cm}$ (NBR 14141) ${ }^{(17)}$, com termos de intensidade ancorados em seus extremos. Ao término do treinamento dos julgadores, quando eles já estavam familiarizados e com as percepções sensoriais memorizadas, foram selecionadas três amostras representativas da variabilidade existente no grupo de amostras a serem avaliadas em cada atributo. Os salames elaborados com as diferentes culturas starters e concentração de substrato, após 60 dias de shelf life, foram avaliados através do teste perfil de característica realizado por equipe treinada da empresa para desenvolver um registro permanente do produto, enfocando componentes sensoriais de seus ingredientes. A análise descritiva quantitativa foi mensurada através de pontos, avaliando-se a aparência, cor, sabor, textura da amostra, em ordem de detecção. Utilizou-se uma escala de valores de 1 a 5, em que 1 é péssimo/extremamente ácido, 2 é regular/muito ácido, 3 é bom/ácido, 4 é muito bom/pouco ácido e 5 é excelente/suave acidez. As amostras de salame utilizadas na análise sensorial para avaliação dos provadores foram cortadas em fatias de $1,5 \mathrm{~mm}$ de espessura, pesando 4,5 g. Cada provador recebeu as fatias de cada amostra, distribuídas em recipientes idênticos de vidro, codificados com números de três dígitos e acompanhados de um copo de água mineral (branco) a temperatura ambiente, a ser utilizados pelo provador antes e entre as degustações das amostras. O julgador foi orientado a tomar o cuidado de fazer uma avaliação por vez, anotando sua nota para cada característica, preenchendo a ficha de avaliação do teste perfil de características.

Todos os dados foram obtidos em triplicata e os resultados foram analisados por ANOVA seguido de teste de Tukey para comparação entre as diferentes culturas starters e pelo teste t-Student para comparar os diferentes teores de açúcar, ambos com 95\% de confiança, com auxílio do software Statistica versão 5.0.

\section{Resultados e Discussão}

O tempo e a temperatura representam um binômio importante no controle do desempenho das culturas microbianas. A temperatura interna do salame manteve-se na maior parte do processo de defumação entre 20 a $30^{\circ} \mathrm{C}$ (Figura 1). Essa faixa de operação de temperatura é considerada adequada e muito importante na etapa de fermentação devido à seleção que acontece de bactérias lácticas e isso passa 
a provocar a acidificação do produto. Essa temperatura também influencia no crescimento de Micrococus (Staphylococcus coagulase positiva), que são responsáveis pela redução do nitrato a nitrito, contribuindo ainda para o desenvolvimento de sabor e aroma. As linhagens de L. plantarum se desenvolvem dentro da faixa de $15{ }^{\circ} \mathrm{C}$ até $40{ }^{\circ} \mathrm{C}$, enquanto o $S$. carnosus desenvolve-se normalmente na faixa de $10{ }^{\circ} \mathrm{C}$ até $45^{\circ} \mathrm{C}^{(18)}$. Deste modo, a temperatura de defumação utilizada neste trabalho está dentro da faixa ótima de crescimento das culturas, embora a taxa de crescimento bacteriano e a quantidade de ácido formado possam ser influenciadas também pela quantidade e tipo de açúcar adicionado ${ }^{(9)}$.

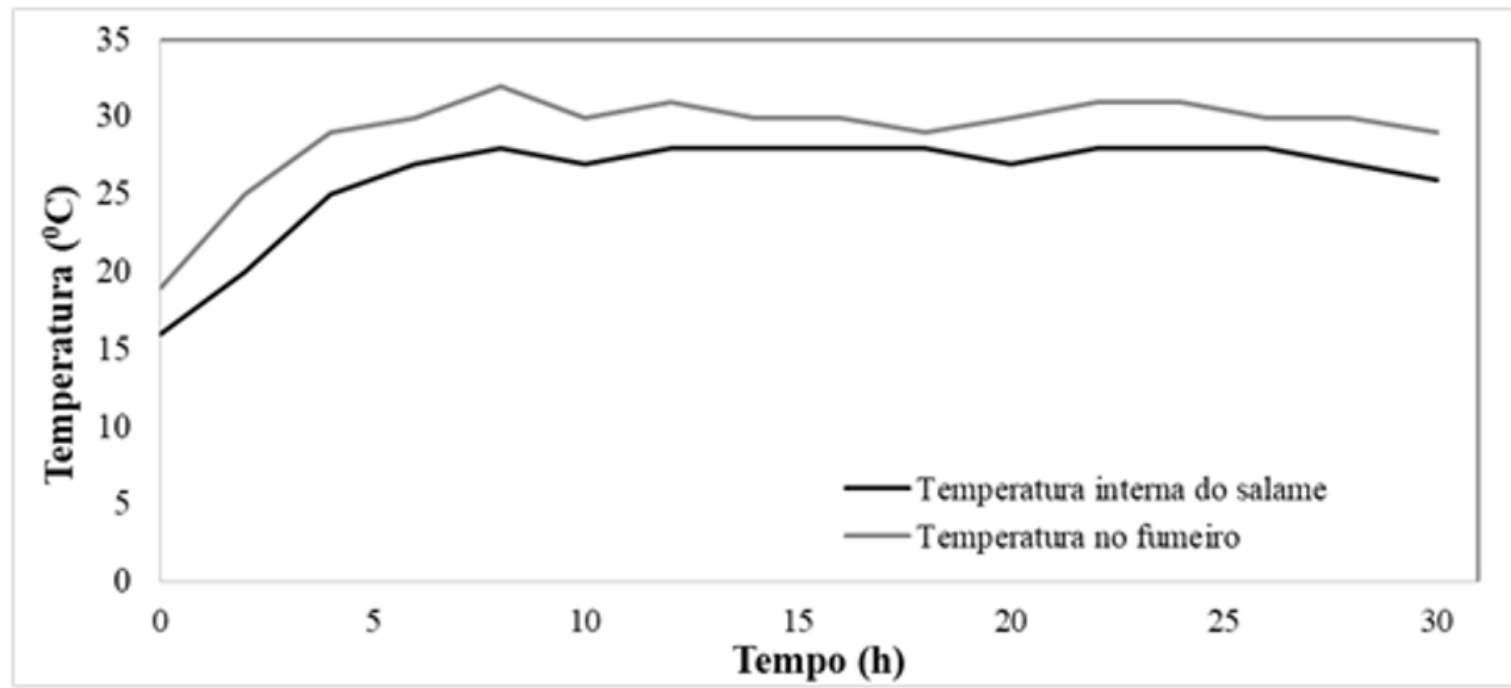

Fonte: Elaboração própria.

Figura 1. Valores de temperatura do fumeiro e temperatura interna do Salame Tipo Italiano durante a fermentação.

$\mathrm{Na}$ maturação do salame, a umidade relativa da sala diminuiu gradativamente de 80 para $60 \%$, o que é importante para a manutenção dessa umidade no interior do produto. A umidade desse produto teve uma redução de 5\% após três dias de fabricação. A redução da umidade e, consequentemente, da Aw é muito importante em produtos embutidos, pois ocorrem durante a etapa de maturação o desenvolvimento da textura e do flavour, as quais dependem de fermentação lática eficiente ${ }^{(19)}$. Uma maturação de salame eficiente deverá ser realizada com uma umidade inicial de aproximadamente $95 \%$ e essa umidade deve ser reduzida durante três a quatro dias para $85 \%{ }^{(20)}$.

$\mathrm{Na}$ Figura 2 estão apresentados os valores de $\mathrm{pH}$ das amostras de salame durante as etapas de defumação, maturação e shelf life, podendo ser observado uma redução do $\mathrm{pH}$ a partir de $16 \mathrm{~h}$ no fumeiro para ambas as concentrações de substrato estudados. Essa redução pode ser explicada pela fermentação da massa, em que ocorre o consumo do substrato pelas bactérias com a produção de ácido lático. Durante a maturação, o comportamento do $\mathrm{pH}$ foi similar para todas as formulações estudadas.

Em trabalho ${ }^{(21)}$ utilizando culturas iniciadoras comerciais, observou-se que embutidos inoculados com a mistura das culturas $S$. carnosus e L. pentosus atingiram valor de $\mathrm{pH}$ em torno de 5,2, no segundo e terceiro dia de fermentação, enquanto aqueles inoculados com a mistura das culturas $S$. xylosus e Pediococcus pentosaceus somente atingiram esse valor no quinto dia. No presente estudo, verificou-se, portanto, que a combinação das diferentes culturas starters apresentaram o mesmo comportamento, com declínio do $\mathrm{pH}$ durante a fermentação (4,8 - 4,9 após 2 dias), comportamento 
típico deste tipo de produto. Esse comportamento é muito importante para a produção de salames de alta qualidade com segurança alimentar devido à inibição de micro-organismos indesejáveis, conversão e estabilização da cor e formação de compostos desejáveis de sabor e $\operatorname{aroma}^{(1,7)}$.

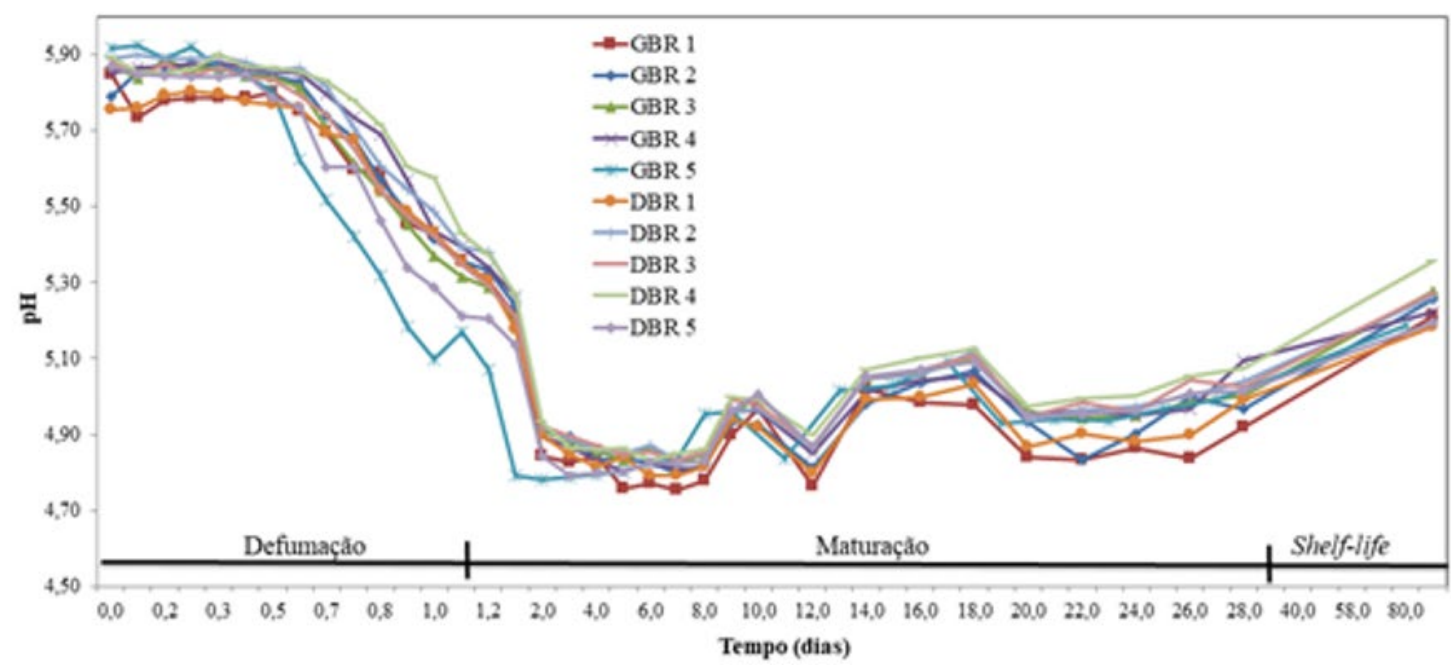

Fonte: Elaboração própria.

Figura 2. Valores de pH durante a etapa de defumação, maturação e shelf life do Salame Tipo Italiano.

Os valores de $\mathrm{pH}$ do Salame Tipo Italiano com diferentes culturas starter, durante a defumação, reduziram com o tempo, em ambas as concentrações do substrato estudado. Os resultados mostraram que houve diferença significativa, em nível de $95 \%$, para as culturas starters durante todo o processo de defumação, contudo, ao final desse processo (30h), não houve diferença em relação ao pH com menor concentração de substrato (Tabela 2).

Observou-se uma tendência de redução do $\mathrm{pH}$ com o uso de culturas $S$. xylosus, S. carnosus e L. sakei nos salames das formulações DBR1 e GBR1 e culturas $S$. carnosus e $L$. sakei nas formulações DBR5 e GBR5, embora com variações nos diferentes tempos de defumação (Tabela 2). O tipo de açúcar (dextrose ou glicose) nas diferentes combinações com as culturas starters não apresentou influência na variação do $\mathrm{pH}(\mathrm{p}>0,05)$, com apenas 2 exceções.

A atividade proteolítica das cepas de micrococos e estafilococos é conhecida pela produção de proteases capazes de induzir a degradação das proteínas da carne, que resultam na liberação de peptídeos e aminoácidos ${ }^{(22)}$. Também no início da fermentação o ácido produzido pelas bactérias lácticas altera o pH. Em relação aos resultados do $\mathrm{pH}$ com o uso de 40,5\% de substrato nas diferentes culturas, houve variações nos valores de $\mathrm{pH}$ em todos os tempos de análise de defumação do salame (Tabela 2). A partir de $16 \mathrm{~h}$ de defumação, a formulação GBR5 apresentou o menor pH em comparação com as demais formulações com o mesmo substrato.

$\mathrm{O}$ pH de salames tradicionais variam entre 4,67 a 6,09 durante a vida útil ${ }^{(23)}$. Estudos realizados em salames fermentados demonstraram que $S$. carnosus crescem a temperatura de $15{ }^{\circ} \mathrm{C}$ e $20^{\circ} \mathrm{C}$, apresentando valores de $\mathrm{pH}$ no produto de 5 e $5,5^{(24-25)}$. No presente estudo, as temperaturas durante a defumação variaram entre 25 e $30^{\circ} \mathrm{C}$ na maior parte do processo e os valores de $\mathrm{pH}$ após $30 \mathrm{~h}$ (defumação) ficaram entre 5,07 e 5,27. 
Tabela 2. Valores de pH do Salame Tipo Italiano nas diferentes formulações com as diferentes culturas starters e concentrações de substrato durante a defumação

\begin{tabular}{|c|c|c|c|c|c|}
\hline \multirow{2}{*}{ Tempo (h) } & \multicolumn{5}{|c|}{ pH } \\
\hline & DBRl & DBR2 & DBR3 & DBR4 & DBR5 \\
\hline 0 & $5,76^{\mathrm{b}, \mathrm{B}} \pm 0,03$ & $5,89^{2,4} \pm 0,02$ & $5,88^{2, A} \pm 0,06$ & $5,89^{2, A} \pm 0,07$ & $5,87^{\mathrm{ab}, A} \pm 0,04$ \\
\hline 2 & $5,76^{\mathrm{b}, \mathrm{A}} \pm 0,02$ & $5,90^{2, A} \pm 0,01$ & $5,84^{24} \pm 0,02$ & $5,86^{24} \pm 0,06$ & $5,85^{\mathrm{a}, \mathrm{B}} \pm 0,01$ \\
\hline 4 & $5,79^{b, A} \pm 0,01$ & $5,89^{2,1} \pm 0,01$ & $5,88^{\mathrm{ab}, \mathrm{A}} \pm 0,02$ & $5,85^{\mathrm{ab}, \mathrm{A}} \pm 0,05$ & $5,85^{\mathrm{ab}, \mathrm{B}} \pm 0,04$ \\
\hline 6 & $5,80^{\mathrm{c} A \mathrm{~A}} \pm 0,01$ & $5,89^{2, A} \pm 0,00$ & $5,85^{\mathrm{b}, \mathrm{A}} \pm 0,02$ & $5,86^{2 b, A} \pm 0,02$ & $5,84^{\mathrm{b}, \mathrm{A}} \pm 0,01$ \\
\hline 8 & $5,80^{\mathrm{A} A} \pm 0,01$ & $5,90^{24} \pm 0,02$ & $5,87^{\mathrm{ab}, \mathrm{A}} \pm 0,03$ & $5,90^{24} \pm 0,02$ & $5,84^{\mathrm{bc}, \mathrm{B}} \pm 0,02$ \\
\hline 10 & $5,78^{\mathrm{b}, \mathrm{A}} \pm 0,02$ & $5,88^{24} \pm 0,03$ & $5,84^{24} \pm 0,03$ & $5,87^{2, A} \pm 0,01$ & $5,85^{24} \pm 0,03$ \\
\hline 12 & $5,77^{\mathrm{b}, \mathrm{A}} \pm 0,02$ & $5,86^{2, \lambda} \pm 0,01$ & $5,83^{2 A} \pm 0,01$ & $5,87^{2 A} \pm 0,02$ & $5,79^{\mathrm{b}, \mathrm{B}} \pm 0,01$ \\
\hline 14 & $5,76^{\mathrm{b}, \mathrm{A}} \pm 0,01$ & $5,87^{24} \pm 0,03$ & $5,79^{\mathrm{b}, \mathrm{A}} \pm 0,01$ & $5,86^{2 A} \pm 0,01$ & $5,76^{\mathrm{b}, \mathrm{B}} \pm 0,01$ \\
\hline 16 & $5,69^{\mathrm{bc}, \mathrm{A}} \pm 0,05$ & $5,82^{24} \pm 0,04$ & $5,74^{2 b, A} \pm 0,01$ & $5,83^{2,4} \pm 0,00$ & $5,60^{\mathrm{A} A} \pm 0,06$ \\
\hline 18 & $5,68^{\mathrm{bc}, \mathrm{A}} \pm 0,03$ & $5,71^{2 b, A} \pm 0,01$ & $5,65^{\mathrm{bc}, \mathrm{A}} \pm 0,02$ & $5,78^{24} \pm 0,02$ & $5,60^{\mathrm{CA}} \pm 0,06$ \\
\hline 20 & $5,54^{\mathrm{bc}, \mathrm{A}} \pm 0,03$ & $5,61^{2 b, A} \pm 0,02$ & $5,54^{\mathrm{bc}, \mathrm{A}} \pm 0,06$ & $5,71^{24} \pm 0,05$ & $5,46^{\mathrm{CA}} \pm 0,06$ \\
\hline 22 & $5,49^{b, A} \pm 0,02$ & $5,55^{\mathrm{ab}, A} \pm 0,02$ & $5,47^{\mathrm{b}, \mathrm{A}} \pm 0,03$ & $5,60^{2 A} \pm 0,05$ & $5,34^{\mathrm{cA}} \pm 0,07$ \\
\hline 24 & $5,43^{\mathrm{b}, \mathrm{A}} \pm 0,04$ & $5,49^{\mathrm{b}, \mathrm{A}} \pm 0,02$ & $5,42^{\mathrm{b}, \mathrm{A}} \pm 0,01$ & $5,58^{2, A} \pm 0,05$ & $5,29^{\mathrm{c}, \mathrm{B}} \pm 0,03$ \\
\hline 26 & $5,35^{24} \pm 0,06$ & $5,39^{2, A} \pm 0,02$ & $5,35^{2 A} \pm 0,04$ & $5,43^{2, A} \pm 0,04$ & $5,21^{\mathrm{b}, \mathrm{B}} \pm 0,05$ \\
\hline 28 & $5,30^{2 b, A} \pm 0,03$ & $5,38^{24} \pm 0,02$ & $5,29^{\mathrm{bc}, A} \pm 0,02$ & $5,37^{2 b, A} \pm 0,05$ & $5,20^{\circ A} \pm 0,04$ \\
\hline \multirow[t]{2}{*}{30} & $5,18^{2, A} \pm 0,04$ & $5,26^{2} A \pm 0,06$ & $5,21^{2, A} \pm 0,03$ & $5,27^{24} \pm 0,09$ & $5,14^{2 A} \pm 0,02$ \\
\hline & GBRI & GBR2 & GBR3 & GBR4 & GBR5 \\
\hline $\mathbf{0}$ & $5,85^{a b, A} \pm 0,03$ & $5,79^{b, 8} \pm 0,03$ & $5,87^{2, A} \pm 0,01$ & $5,85^{2 b, A} \pm 0,02$ & $5,83^{\mathrm{ab}, A} \pm 0,03$ \\
\hline 2 & $5,74^{\mathrm{b}, \mathrm{A}} \pm 0,04$ & $5,86^{24} \pm 0,05$ & $5,84^{2 A} \pm 0,02$ & $5,87^{24} \pm 0,02$ & $5,92^{24} \pm 0,01$ \\
\hline 4 & $5,78^{c A} \pm 0,02$ & $5,85^{\mathrm{b}, \mathrm{A}} \pm 0,03$ & $5,89^{2 b, A} \pm 0,01$ & $5,87^{\mathrm{b}, \mathrm{A}} \pm 0,02$ & $5,92^{2 A} \pm 0,01$ \\
\hline 6 & $5,79^{b, A} \pm 0,01$ & $5,88^{2 A} \pm 0,01$ & $5,87^{2 b, A} \pm 0,05$ & $5,88^{2, A} \pm 0,02$ & $5,89^{2 A} \pm 0,03$ \\
\hline 8 & $5,79^{\mathrm{CA}} \pm 0,01$ & $5,87^{\mathrm{b}, \mathrm{A}} \pm 0,02$ & $5,87^{\mathrm{b}, \mathrm{A}} \pm 0,02$ & $5,88^{\mathrm{b}, \mathrm{A}} \pm 0,01$ & $5,92^{24} \pm 0,02$ \\
\hline 10 & $5,79^{\mathrm{b}, A} \pm 0,02$ & $5,85^{24} \pm 0,02$ & $5,85^{2 A} \pm 0,03$ & $5,87^{24} \pm 0,02$ & $5,87^{2 A} \pm 0,01$ \\
\hline 12 & $5,80^{b, A} \pm 0,01$ & $5,85^{2, A} \pm 0,02$ & $5,84^{2 A} \pm 0,01$ & $5,86^{2}, A 0,02$ & $5,85^{2 A} \pm 0,01$ \\
\hline 14 & $5,75^{\mathrm{b}, \mathrm{A}} \pm 0,02$ & $5,83^{24} \pm 0,02$ & $5,81^{2 A} \pm 0,03$ & $5,85^{24} \pm 0,02$ & $5,80^{2 b, A} \pm 0,03$ \\
\hline 16 & $5,70^{\mathrm{b} C, \mathrm{~A}} \pm 0,02$ & $5,74^{2 b, A} \pm 0,02$ & $5,71^{\mathrm{b}, \mathrm{A}} \pm 0,03$ & $5,80^{2, A} \pm 0,04$ & $5,62^{\mathrm{cA}} \pm 0,04$ \\
\hline 18 & $5,60^{\mathrm{bc}, \mathrm{A}} \pm 0,08$ & $5,68^{a b, A} \pm 0,03$ & $5,61^{a b c, A} \pm 0,04$ & $5,73^{\mathrm{a}, \mathrm{B}} \pm 0,02$ & $5,52^{\mathrm{cA}} \pm 0,02$ \\
\hline 20 & $5,59^{2 b, A} \pm 0,02$ & $5,57^{\mathrm{b}, \mathrm{A}} \pm 0,05$ & $5,54^{\mathrm{b}, \mathrm{A}} \pm 0,03$ & $5,69^{2, A} \pm 0,00$ & $5,42^{\mathrm{cA}} \pm 0,06$ \\
\hline 22 & $5,46^{24} \pm 0,05$ & $5,48^{\mathrm{a}, \mathrm{B}} \pm 0,02$ & $5,45^{24} \pm 0,03$ & $5,57^{24} \pm 0,05$ & $5,32^{\mathrm{b}, \mathrm{A}} \pm 0,06$ \\
\hline 24 & $5,43^{2, A} \pm 0,02$ & $5,41^{\mathrm{a}, \mathrm{B}} \pm 0,01$ & $5,37^{2, A} \pm 0,03$ & $5,44^{\mathrm{a}, \mathrm{B}} \pm 0,01$ & $5,18^{\mathrm{b}, \mathrm{A}} \pm 0,05$ \\
\hline 26 & $5,36^{\mathrm{ab}, A} \pm 0,02$ & $5,36^{2 b, A} \pm 0,02$ & $5,31^{\mathrm{b}, \mathrm{A}} \pm 0,03$ & $5,39^{2, A} \pm 0,02$ & $5,10^{\mathrm{CA}} \pm 0,03$ \\
\hline 28 & $5,30^{2 A} \pm 0,01$ & $5,33^{24} \pm 0,06$ & $5,29^{24} \pm 0,02$ & $5,34^{24} \pm 0,07$ & $5,17^{\mathrm{b}, \mathrm{A}} \pm 0,01$ \\
\hline 30 & $5,21^{2, A} \pm 0,03$ & $5,24^{2, A} \pm 0,03$ & $5,21^{2 A} \pm 0,02$ & $5,26^{2}, 4 \pm 0,05$ & $5,07^{\mathrm{b}, \mathrm{A}} \pm 0,06$ \\
\hline
\end{tabular}

Fonte: Elaboração própria. Média (três repetições) \pm Desvio Padrão seguidas de letras iguais minúsculas na linha no mesmo dia indicam não haver diferença significativa em nível de $5 \%$ (teste de Tukey) e maiúsculas iguais na columa no mesmo dia de análise indicam não haver diferença significativa em nivel de $5 \%$ ( $T$-student $)$.

Os valores de $\mathrm{pH}$ na etapa de maturação do salame (Tabela 3) para as formulações DBR1 e GBR1, DBR3 e GBR3, em relação às culturas starters não apresentaram diferença significativa $(\mathrm{p}>0,05)$. No mesmo dia de análise para as formulações DBR2 e GBR2 apresentaram diferença significativa $(\mathrm{p}<0,05)$ entre as concentrações de substrato no tempo de 14 e 22 dias, as formulações DBR4 e GBR4 no tempo de 5 e 7 dias, e as formulações DBR5 e GBR5 no tempo inicial.

A partir do sétimo dia de maturação dos salames, os valores de $\mathrm{pH}$ apresentaram um aumento (4,79 a 5,04, e 4,75 a 5,10 para os tratamentos com 40,5 e 99,5\% de substrato, respectivamente). Esse aumento ocorre devido às reações de descarboxilação e desaminação de aminoácidos, que liberam 
amônia no meio, alcalinizando-o ${ }^{(1,7)}$. Esse comportamento nos valores de $\mathrm{pH}$ também foi observado no presente estudo.

Tabela 3. Valores de pH do Salame Tipo Italiano nas diferentes formulações com as diferentes culturas starters e concentrações de substrato durante a maturação

\begin{tabular}{|c|c|c|c|c|c|}
\hline \multirow{2}{*}{ Tempo (dias) } & \multicolumn{5}{|c|}{ pH } \\
\hline & DBRI & DBR2 & DBR3 & DBR4 & DBR5 \\
\hline 2 & $4,90^{2, A} \pm 0,02$ & $4,92^{2, A} \pm 0,02$ & $4,92^{2, A} \pm 0,02$ & $4,93^{2, A} \pm 0,03$ & $4,84^{\mathrm{b}, A} \pm 0,02$ \\
\hline 3 & $4,85^{\mathrm{ab}, \mathrm{A}} \pm 0,02$ & $4,89^{2, A} \pm 0,06$ & $4,89^{2, A} \pm 0,03$ & $4,86^{2 b, A} \pm 0,01$ & $4,79^{\mathrm{b}, \mathrm{A}} \pm 0,01$ \\
\hline 4 & $4,82^{\mathrm{b}, \mathrm{A}} \pm 0,02$ & $4,86^{2, A} \pm 0,02$ & $4,87^{2, A} \pm 0,02$ & $4,86^{2, A} \pm 0,00$ & $4,80^{\mathrm{b}, \mathrm{A}} \pm 0,00$ \\
\hline 5 & $4,84^{2, A} \pm 0,04$ & $4,85^{2, A} \pm 0,03$ & $4,85^{2, A} \pm 0,01$ & $4,86^{2, A} \pm 0,02$ & $4,80^{2 A} \pm 0,01$ \\
\hline 6 & $4,79^{\mathrm{b}, \mathrm{A}} \pm 0,03$ & $4,87^{2, A} \pm 0,01$ & $4,85^{a b, A} \pm 0,04$ & $4,83^{2 b, A} \pm 0,02$ & $4,83^{a b, A} \pm 0,03$ \\
\hline 7 & $4,79^{\mathrm{b}, \mathrm{A}} \pm 0,01$ & $4,83^{2, A} \pm 0,01$ & $4,83^{2, A} \pm 0,02$ & $4,85^{2, A} \pm 0,01$ & $4,82^{a b, A} \pm 0,02$ \\
\hline 8 & $4,82^{2, A} \pm 0,04$ & $4,85^{2, A} \pm 0,03$ & $4,85^{2, A} \pm 0,02$ & $4,86^{2, A} \pm 0,00$ & $4,83^{24} \pm 0,01$ \\
\hline 9 & $4,94^{2, A} \pm 0,04$ & $4,96^{2, A} \pm 0,04$ & $4,99^{2, \wedge} \pm 0,03$ & $5,00^{2, A} \pm 0,04$ & $4,96^{21} \pm 0,03$ \\
\hline 10 & $4,92^{\mathrm{b}, \mathrm{A}} \pm 0,04$ & $4,97^{2 \mathrm{~b}, \mathrm{~A}} \pm 0,02$ & $4,98^{\mathrm{ab}, \mathrm{A}} \pm 0,03$ & $4,99^{2 b, A} \pm 0,03$ & $5,01^{2 \lambda} \pm 0,01$ \\
\hline 12 & $4,80^{\mathrm{b}, \mathrm{A}} \pm 0,04$ & $4,87^{2, A} \pm 0,01$ & $4,87^{2, A} \pm 0,01$ & $4,90^{2, A} \pm 0,03$ & $4,87^{24} \pm 0,02$ \\
\hline 14 & $4,99^{\mathrm{b}, \mathrm{A}} \pm 0,02$ & $5,04^{2, A} \pm 0,02$ & $5,05^{2 A} \pm 0,01$ & $5,07^{2, A} \pm 0,03$ & $5,05^{2 A} \pm 0,01$ \\
\hline 16 & $5,00^{\mathrm{b}, \mathrm{A}} \pm 0,04$ & $5,06^{\mathrm{ab}, \mathrm{A}} \pm 0,02$ & $5,07^{2, A} \pm 0,01$ & $5,10^{2, A} \pm 0,03$ & $5,07^{24} \pm 0,00$ \\
\hline 18 & $5,03^{\mathrm{b}, \mathrm{A}} \pm 0,02$ & $5,12^{2, A} \pm 0,03$ & $5,11^{2, A} \pm 0,02$ & $5,13^{2, A} \pm 0,04$ & $5,09^{a b, A} \pm 0,00$ \\
\hline 20 & $4,87^{\mathrm{b}, \mathrm{A}} \pm 0,03$ & $4,94^{2, A} \pm 0,02$ & $4,95^{2, A} \pm 0,02$ & $4,97^{2, A} \pm 0,03$ & $4,95^{2 \lambda} \pm 0,03$ \\
\hline 22 & $4,90^{\mathrm{b}, \mathrm{A}} \pm 0,03$ & $4,96^{2 b, A} \pm 0,01$ & $4,98^{2, A} \pm 0,03$ & $4,99^{2, A} \pm 0,03$ & $4,95^{\mathrm{ab}, \mathrm{A}} \pm 0,03$ \\
\hline 24 & $4,88^{\mathrm{b}, \mathrm{A}} \pm 0,04$ & $4,97^{2, A} \pm 0,01$ & $4,96^{2, A} \pm 0,02$ & $5,00^{2, A} \pm 0,03$ & $4,96^{2,4} \pm 0,02$ \\
\hline 26 & $4,90^{\mathrm{b}, \mathrm{A}} \pm 0,04$ & $5,00^{2 b, A} \pm 0,02$ & $5,04^{2, A} \pm 0,05$ & $5,05^{2, A} \pm 0,05$ & $5,01^{2 \lambda} \pm 0,04$ \\
\hline \multirow[t]{2}{*}{28} & $4,99^{\mathrm{b}, \mathrm{A}} \pm 0,04$ & $5,04^{2 b, A} \pm 0,00$ & $5,03^{a b, A} \pm 0,01$ & $5,07^{2, A} \pm 0,03$ & $5,02^{a b, A} \pm 0,03$ \\
\hline & GBRl & GBR2 & GBR3 & GBR4 & GBR5 \\
\hline 2 & $4,84^{2 b, A} \pm 0,06$ & $4,91^{2, A} \pm 0,02$ & $4,91^{2, A} \pm 0,01$ & $4,89^{2, A} \pm 0,03$ & $4,79^{\mathrm{b}, \mathrm{B}} \pm 0,02$ \\
\hline 3 & $4,83^{\mathrm{ab}, A} \pm 0,06$ & $4,89^{2, A} \pm 0,03$ & $4,88^{2, A} \pm 0,02$ & $4,87^{2 b, A} \pm 0,04$ & $4,78^{\mathrm{b}, \mathrm{A}} \pm 0,01$ \\
\hline 4 & $4,84^{\mathrm{ab}, \mathrm{A}} \pm 0,04$ & $4,83^{\mathrm{ab}, \mathrm{A}} \pm 0,02$ & $4,86^{2, A} \pm 0,02$ & $4,83^{2 b, A} \pm 0,02$ & $4,79^{\mathrm{b}, \mathrm{A}} \pm 0,03$ \\
\hline 5 & $4,76^{2, A} \pm 0,05$ & $4,84^{2, A} \pm 0,04$ & $4,83^{2, A} \pm 0,03$ & $4,80^{2, B} \pm 0,02$ & $4,79^{2 \lambda} \pm 0,02$ \\
\hline 6 & $4,77^{2, A} \pm 0,02$ & $4,83^{2, A} \pm 0,03$ & $4,86^{2, A} \pm 0,05$ & $4,83^{2, A} \pm 0,06$ & $4,80^{21} \pm 0,02$ \\
\hline 7 & $4,75^{2, A} \pm 0,05$ & $4,80^{2, A} \pm 0,06$ & $4,82^{2, A} \pm 0,03$ & $4,81^{\mathrm{a}, \mathrm{B}} \pm 0,02$ & $4,83^{21} \pm 0,01$ \\
\hline 8 & $4,78^{2, A} \pm 0,03$ & $4,82^{2, A} \pm 0,02$ & $4,85^{2, A} \pm 0,04$ & $4,81^{2, A} \pm 0,03$ & $4,83^{24} \pm 0,02$ \\
\hline 9 & $4,90^{2, A} \pm 0,04$ & $4,93^{2, A} \pm 0,01$ & $4,95^{2 \wedge} \pm 0,02$ & $4,96^{2, A} \pm 0,03$ & $4,95^{2 \lambda} \pm 0,04$ \\
\hline 10 & $4,97^{\mathrm{ab}, \mathrm{A}} \pm 0,02$ & $4,93^{\mathrm{b}, \mathrm{A}} \pm 0,01$ & $5,01^{2 A} \pm 0,04$ & $4,96^{2 b, A} \pm 0,03$ & $4,96^{\mathrm{ab}, \mathrm{A}} \pm 0,03$ \\
\hline 12 & $4,76^{\mathrm{b}, \mathrm{A}} \pm 0,02$ & $4,81^{2 b, A} \pm 0,03$ & $4,86^{2, A} \pm 0,05$ & $4,85^{\mathrm{ab}, A} \pm 0,05$ & $4,84^{a b, A} \pm 0,03$ \\
\hline 14 & $5,02^{2, A} \pm 0,03$ & $4,98^{\mathrm{a}, \mathrm{B}} \pm 0,03$ & $4,05^{2, A} \pm 0,05$ & $5,01^{2, A} \pm 0,05$ & $5,02^{24} \pm 0,02$ \\
\hline 16 & $4,98^{2, A} \pm 0,04$ & $5,04^{2, A} \pm 0,04$ & $5,06^{2, A} \pm 0,02$ & $5,04^{2, A} \pm 0,05$ & $5,03^{2 \lambda} \pm 0,02$ \\
\hline 18 & $4,98^{2, A} \pm 0,06$ & $5,07^{2, A} \pm 0,07$ & $5,10^{2, A} \pm 0,04$ & $5,05^{2, A} \pm 0,05$ & $5,09^{2 \lambda} \pm 0,06$ \\
\hline 20 & $4,84^{2, A} \pm 0,03$ & $4,93^{2, A} \pm 0,06$ & $4,96^{2 \wedge} \pm 0,04$ & $4,95^{2, A} \pm 0,07$ & $4,93^{2 A} \pm 0,04$ \\
\hline 22 & $4,84^{2, A} \pm 0,05$ & $4,83^{\mathrm{a}, \mathrm{B}} \pm 0,05$ & $4,94^{2, A} \pm 0,05$ & $4,96^{\mathrm{a}, \mathrm{A}} \pm 0,06$ & $4,94^{24} \pm 0,05$ \\
\hline 24 & $4,86^{2, A} \pm 0,06$ & $4,90^{2, A} \pm 0,03$ & $4,95^{2, A} \pm 0,05$ & $4,95^{2, A} \pm 0,04$ & $4,94^{2 \lambda} \pm 0,05$ \\
\hline 26 & $4,84^{2, A} \pm 0,03$ & $5,00^{2, A} \pm 0,06$ & $4,98^{2, A} \pm 0,06$ & $4,97^{2, A} \pm 0,04$ & $4,97^{21} \pm 0,02$ \\
\hline 28 & $4,92^{2, A} \pm 0,07$ & $4,97^{2, A} \pm 0,05$ & $5,00^{2, A} \pm 0,06$ & $5,10^{2, A} \pm 0,18$ & $4,99^{2 \lambda} \pm 0,04$ \\
\hline
\end{tabular}

Fonte: Elaboração própria. Média (três repetições) \pm Desvio Padrão seguidas de letras minúsculas iguais na linha indicam não haver diferença significativa em nível de $5 \%$ (teste de Tukey) e maiúsculas iguais na coluna no mesmo dia de análise

Os resultados do $\mathrm{pH}$ dos salames durante o shelf life (Tabela 4) nas formulações DBR1 e GBR1, DBR2 e GBR2, DBR3 e GBR3, DBR5 e GBR5 não apresentam diferenças significativas (p>0,05) entre as diferentes concentrações dos substratos avaliadas. Apenas a formulação GBR4 apresentou diferença significativa $(\mathrm{p}<0,05)$ entre os substratos após 88 dias de shelf-life. $\mathrm{O} \mathrm{pH}$ em todas as 
amostras aumentou com o tempo de estudo, efeito atribuído à desaminação de proteínas por ação de leveduras ${ }^{(26)}$ e a capacidade tamponante das proteínas.

Tabela 4. Valores de $\mathrm{pH}$ do Salame Tipo Italiano nas diferentes formulações com as diferentes culturas starters e concentrações de substrato durante o shelf life

\begin{tabular}{|c|c|c|c|c|c|}
\hline \multirow{2}{*}{ Tempo (dias) } & \multicolumn{5}{|c|}{ pH } \\
\hline & DBRl & DBR2 & DBR3 & DBR4 & DBR5 \\
\hline 28 & $4,99^{\mathrm{b}, \mathrm{A}} \pm 0,04$ & $5,04^{2 b, A} \pm 0,02$ & $5,03^{2 b, A} \pm 0,01$ & $5,07^{2 A} \pm 0,03$ & $5,02^{a b, A} \pm 0,03$ \\
\hline 88 & $5,18 \mathrm{AA} \pm 0,03$ & $5,26^{\mathrm{b}, \mathrm{A}} \pm 0,01$ & $5,27^{\mathrm{b}, \mathrm{A}} \pm 0,02$ & $5,36^{2 A} \pm 0,03$ & $5,19^{\wedge A} \pm 0,02$ \\
\hline & GBRl & GBR2 & GBR3 & GBR4 & GBR5 \\
\hline 28 & $4,92^{2 \wedge} \pm 0,07$ & $4,97^{2, A} \pm 0,05$ & $5,00^{2, \lambda} \pm 0,06$ & $5,09^{\mathrm{a}, \mathrm{A}} \pm 0,8$ & $4,99^{2 \lambda} \pm 0,04$ \\
\hline 88 & $5,21^{2 A} \pm 0,05$ & $5,26^{24} \pm 0,04$ & $5,28^{2 A} \pm 0,04$ & $5,22^{\mathrm{a}, \mathrm{B}} \pm 0,05$ & $5,19^{2 x} \pm 0,04$ \\
\hline
\end{tabular}

Fonte: Elaboração própria. Média (três repetições) \pm Desvio Padrão seguidas de letras minúsculas iguais na linha indicam não haver diferença significativa em nivel de $5 \%$ (teste de Tukey) e maiúsculas iguais na coluna no mesmo dia de análise indicam não haver diferença significativa em nível de $5 \%$ ( $T$-student).

Os resultados do $\mathrm{pH}$ nas diferentes culturas starters durante o shelf life com $99,5 \%$ de substrato apresentaram diferenças em nível de 95\% de confiança da amostra DBR4 com as demais, na qual o valor final de $\mathrm{pH}$ para esta amostra foi de 5,36. Usando 40,5\% de substrato não houve diferença no $\mathrm{pH}$ entre as culturas starters, em que o $\mathrm{pH}$ variou de 5,19 a 5,28. O pH aumentou durante os 60 dias de shelf life para todas as culturas, independente da concentração de substrato estudado (Tabela 4).

Os salames brasileiros se distinguem dos produzidos na Europa pela acidez mais branda, com $\mathrm{pH}$ entre 5,2 e 5,4 e pelas características da carne, atribuídas ao manejo da criação, raças dos animais e características de abate ${ }^{(7)}$. Dessa forma, verifica-se que os valores de $\mathrm{pH}$ para todas as formulações encontram-se de acordo com o recomendado por $^{(7)}$ com valor de $\mathrm{pH}$ final em torno de 5,4 após 30 dias de maturação.

Em relação às análises de nitrato durante a defumação do salame, realizadas no tempo 0,14 e $30 \mathrm{~h}$, observou-se que a quantidade de nitrato não diminuiu como era esperado, inclusive aumentando em alguns casos, com variações nos valores atribuídos a elas nas amostras as quais eram destrutivas e pela própria redução de peso das amostras durante a secagem. Considerando a não existência de tendência nos resultados durante a defumação, constatou-se que as variações estatísticas não são válidas para serem discutidas.

Tabela 5. Teores de nitrato no Salame Tipo Italiano nas diferentes formulações com diferentes culturas starters e diferentes concentrações de substrato durante a defumação

\begin{tabular}{cccccc}
\hline \multirow{2}{*}{ Tempo (h) } & \multicolumn{5}{c}{ Nitrato (ppm) } \\
\cline { 2 - 6 } & GBR1 & GBR2 & GBR3 & GBR4 & GBR5 \\
\hline 0 & $278,45^{\mathrm{a}, \mathrm{A}} \pm 2,22$ & $160,57^{\mathrm{d}, \mathrm{A}} \pm 9,79$ & $250,65^{\mathrm{b}, \mathrm{A}} \pm 3,79$ & $186,53^{\mathrm{c}, \mathrm{B}} \pm 4,06$ & $246,24^{\mathrm{b}, \mathrm{A}} \pm 7,07$ \\
14 & $309,01^{\mathrm{a}, \mathrm{A}} \pm 9,05$ & $220,79^{\mathrm{c}, \mathrm{A}} \pm 1,23$ & $224,79^{\mathrm{c}, \mathrm{A}} \pm 7,13$ & $248,52^{\mathrm{b}, \mathrm{B}} \pm 3,79$ & $217,29^{\mathrm{c}, \mathrm{A}} \pm 4,78$ \\
30 & $268,86^{\mathrm{c}, \mathrm{B}} \pm 6,03$ & $325,52^{\mathrm{a}, \mathrm{A}} \pm 0,91$ & $292,48^{\mathrm{b}, \mathrm{B}} \pm 4,87$ & $273,34^{\mathrm{b}, \mathrm{A}} \pm 6,84$ & $225,80^{\mathrm{d}, \mathrm{A}} \pm 6,71$ \\
\hline \multicolumn{7}{c}{} & DBRl & DBR2 & DBR3 & DBR4 & DBR5 \\
\hline 0 & $232,36^{\mathrm{b}, \mathrm{B}} \pm 4,49$ & $201,83^{\mathrm{d}, \mathrm{A}} \pm 1,41$ & $208,19^{\mathrm{cd}, \mathrm{B}} \pm 2,61$ & $273,39^{\mathrm{a}, \mathrm{A}} \pm 2,79$ & $217,19^{\mathrm{c}, \mathrm{A}} \pm 0,60$ \\
14 & $301,58^{\mathrm{a}, \mathrm{A}} \pm 5,28$ & $223,07^{\mathrm{b}, \mathrm{A}} \pm 0,65$ & $174,43^{\mathrm{c}, \mathrm{B}} \pm 8,66$ & $300,11^{\mathrm{a}, \mathrm{A}} \pm 14,46$ & $143,14^{\mathrm{c}, \mathrm{B}} \pm 9,19$ \\
30 & $330,92^{\mathrm{a}, \mathrm{A}} \pm 5,63$ & $302,68^{\mathrm{b}, \mathrm{B}} \pm 1,36$ & $330,95^{\mathrm{a}, \mathrm{A}} \pm 5,39$ & $287,91^{\mathrm{b}, \mathrm{A}} \pm 10,37$ & $240,28^{\mathrm{c}, \mathrm{A}} \pm 7,36$ \\
\hline
\end{tabular}

Fonte: Elaboração própria. Média (três repetições) \pm Desvio Padrão seguidas de letras minúsculas iguais na linha indicam não haver diferença significativa em nível de $5 \%$ (teste de Tukey) e maiúsculas iguais na coluna no mesmo dia de análise indicam não haver diferença significativa em nível de $5 \%$ ( $T$-student). 
S. xylosus apresentam um crescimento ótimo a $30^{\circ} \mathrm{C}, \mathrm{pH} 5,5$ e $20 \% \mathrm{de} \mathrm{NaCl}^{(8)}$. A temperatura ótima de crescimento do S. xylosus é em torno de $30{ }^{\circ} \mathrm{C}$ e nitrito até $200 \mathrm{ppm}$, não se desenvolvendo bem em pH ácido (abaixo de 5,7) ${ }^{(26-27)}$. Neste trabalho, observa-se que a temperatura de fumeiro operou em aproximadamente $30{ }^{\circ} \mathrm{C}$, houve a redução de $\mathrm{pH}$ a níveis menores que 5,5 , porém os resultados de redução de nitrato a nitrito em todas as amostras não aconteceram, ao contrário, aumentaram.

Individualmente, na comparação das culturas com cada concentração de substrato durante a defumação, verificou-se diferença significativa $(\mathrm{p}<0,05)$ na quantidade de nitrito no tempo inicial e após $30 \mathrm{~h}$ para a cultura 1 , em 14 e $30 \mathrm{~h}$ para as culturas 3 e 5, enquanto que para as culturas 2 e 4 não houve diferença entre os substratos no mesmo dia da análise (Tabela 6). Em todas as culturas testadas, a quantidade de nitrito reduziu com o tempo de defumação na comparação entre as concentrações de substratos. A não redução do nitrato a nitrito pode ser uma possível explicação da queda rápida nos teores de nitrito.

Tabela 6. Resultados de nitrito no Salame Tipo Italiano nas diferentes formulações com diferentes culturas starters e diferentes concentrações de substrato durante a defumação

\begin{tabular}{|c|c|c|c|c|c|}
\hline \multirow{2}{*}{ Tempo (h) } & \multicolumn{5}{|c|}{ Nitrito (ppm) } \\
\hline & DBRI & DBR2 & DBR3 & DBR4 & DBR5 \\
\hline 0 & $133,74^{\mathrm{a}, \mathrm{B}} \pm 1,42$ & $136,71^{\mathrm{a}, \mathrm{A}} \pm 1,85$ & $134,57^{\mathrm{a}, \Lambda} \pm 1,11$ & $148,67^{\mathrm{b}, \mathrm{A}} \pm 1,51$ & $146,47^{\mathrm{b}, \AA} \pm 2,14$ \\
\hline 14 & $71,98^{\mathrm{b}, \mathrm{A}} \pm 5,59$ & $91,07^{\mathrm{ab}, \mathrm{A}} \pm 4,92$ & $87,44^{\mathrm{ab}, \mathrm{B}} \pm 5,68$ & $91,71^{\mathrm{ab}, \mathrm{A}} \pm 5,88$ & $97,02^{\mathrm{a}, \mathrm{B}} \pm 1,57$ \\
\hline \multirow[t]{2}{*}{30} & $13,07^{\mathrm{a}, \mathrm{B}} \pm 0,05$ & $25,67^{2 A} \pm 6,41$ & $12,00^{2, \mathrm{~B}} \pm 0,00$ & $23,48^{2 A} \pm 4,61$ & $16,46^{\mathrm{a}, \mathrm{B}} \pm 0,90$ \\
\hline & GBRl & GBR2 & GBR3 & GBR4 & GBR5 \\
\hline 0 & $142,25^{\mathrm{a}, \mathrm{A}} \pm 2,04$ & $145,24^{\mathrm{a}, \mathrm{A}} \pm 5,84$ & $142,08^{\mathrm{a}, \mathrm{A}} \pm 3,54$ & $144,11^{a, A} \pm 0,66$ & $139,83^{2 A} \pm 0,19$ \\
\hline 14 & 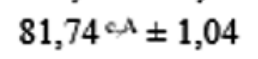 & $90,78^{\mathrm{bc}, \mathrm{A}} \pm 5,58$ & $89,55^{\mathrm{abc}, \mathrm{A}} \pm 0,54$ & $98,97^{\mathrm{ab}, \mathrm{A}} \pm 3,56$ & $106,13^{24} \pm 1,51$ \\
\hline 30 & $23,254 \pm 0,62$ & $22,77^{24} \pm 6,83$ & $19,01^{\mathrm{a}, \mathrm{A}} \pm 0,75$ & $21,25^{2 A} \pm 1,29$ & $22,01^{\mathrm{a}, \mathrm{A}} \pm 1,17$ \\
\hline
\end{tabular}

Fonte: Elaboração própria. Média (três repetições) \pm Desvio Padrão seguidas de letras minúsculas iguais na linha indicam não haver diferença significativa em nível de $5 \%$ (teste de Tukey) e maiúsculas iguais na coluna no mesmo dia de análise indicam não haver diferença significativa em nivel de $5 \%$ (T-student).

A Figura 3 apresenta o comportamento da variação de nitrato (a), nitrito (b) e a soma de ambos (c) durante a defumação, maturação e shelf life das diferentes formulações de salame. A quantidade de nitrato e nitrito nos salames teve uma redução com o tempo no fumeiro. A quantidade de sal de cura final (nitrato e nitrito) nessa etapa teve uma redução influenciada pela intensa decomposição do nitrito em todas as amostras.

Importante destacar que a cultura BR5, utilizando os diferentes substratos, apresenta a maior redução da combinação de nitrato e nitrito. Esse comportamento pode ser atribuído às espécies utilizadas na cultura BR5, pois a redução dos nitratos é realizada pelas bactérias da família Micrococaceae, durante as primeiras $24 \mathrm{~h}$, quando os níveis de ácido lático ainda estão elevados ${ }^{(24)}$. Essas bactérias possuem um sistema nitrato e nitrito redutase que favorece a ocorrência das reações de cura responsáveis pela coloração típica destes produtos cárneos.

Analisando a Figura 3 (a), o aumento dos valores de nitrato é justificado pelo fato que o salame está diminuindo seu peso nesse processo de maturação, porém, sem redução de nitrato em nitrito que é necessária para prolongar a ação do nitrito no produto. Esperava-se minimizar esse defeito tecnológico alterando-se as culturas starter e a concentração do substrato, no entanto, sem resultados satisfatórios.

Nota-se que a redução de nitrito (Figura 3 b) continua acontecendo até aproximadamente o $12^{\circ}$ dia de cura, após esse tempo demonstra um comportamento semelhante à redução dos nitratos. Vale salientar 
que o nível de nitrito residual nessa etapa é extremamente baixo em todas as amostras, ou seja, abaixo de 7 ppm. Dessa forma, quando somados esses valores (Figura $3 \mathrm{c}$ ), o nitrito tem pouca influência no comportamento. Esse resultado não atende à Legislação Instrução Normativa $\mathrm{N}^{0} 51$, de dezembro de 2006, que preconiza a quantidade máxima de somatória de nitrato + nitrito em 150 ppm ${ }^{(28)}$. Neste sentido, a aplicação somente de nitrito na concentração permitida pela legislação torna-se uma alternativa tecnológica aplicável.

A amostra com menor quantidade de substrato (40,5\%) teve o mesmo comportamento que a maior (99,5\%), na qual a quantidade de sal de cura final (nitrato + nitrito) também teve uma redução influenciada pela intensa decomposição do nitrito, nas mesmas proporções em todas as amostras. Contudo, a formulação GBR5 foi a que apresentou a maior redução, atendendo a especificação ${ }^{(28)}$, na qual o valor residual de nitrato + nitrito foi de $118,58 \mathrm{ppm}$.

A Figura 3 (c) apresenta o comportamento de nitrato e nitrito em todas as formulações com as diferentes culturas starters e concentrações de substrato durante a maturação e shelf life. Pode ser visto que os resultados de nitrato e da soma (nitrito + nitrato) variaram para cada amostra. Em relação ao nitrito, todas as amostras tiveram comportamento similar, pois diminuíram consideravelmente ainda nos primeiros dias de cura.

A formulação GBR5 com 40,5\% de substrato apresentou maior redução das quantidades de nitrito + nitrato, sendo a única amostra a atender à Instrução Normativa $51^{(28)}$, que adota o regulamento técnico de atribuições de aditivos e seus limites das categorias de alimentos - carnes e produtos cárneos. Essa maior redução de nitrato na formulação GBR5 se deve a maior redução inicial, observada nas primeiras 30h (defumação) em relação às demais amostras com manutenção desta tendência durante a maturação do salame. Em todas as amostras, o nitrito chegou a níveis muito próximos a zero. Desse modo, o nitrato foi o responsável pelos altos níveis residuais no produto não atendendo à legislação. O nitrato é efetivo como agente de cura somente se for reduzido a nitrito e essa redução depende tipicamente de microorganismos, tempo e temperatura adequadas ${ }^{(29)}$. Uma possível explicação para a não redução do nitrato é a velocidade e intensidade da acidificação do meio ${ }^{(7)}$.

Os resultados das análises de umidade das formulações dos salames na defumação (tempos 0 e 30h) estão apresentados na Tabela 7. No tempo inicial (0h), as formulações DBR1, DBR2, DBR4, GBR1, GBR2 e GBR5 diferiram estatisticamente $(\mathrm{p}<0,05)$. As formulações DBR3 e DBR5, GBR3 e GBR5 não apresentaram diferença significativa entre si $(p>0,05)$. No tempo $30 \mathrm{~h}$, todas as culturas diferiram entre si.

De maneira geral, observa-se uma menor umidade com as culturas 1 e 2 em relação às demais, nos tempos 0 e 30h de defumação, com exceção à cultura 2 com 99,5\% de substrato no tempo inicial. Como esperado, todas as amostras apresentaram menor umidade com $30 \mathrm{~h}$ de defumação em relação ao tempo inicial. 


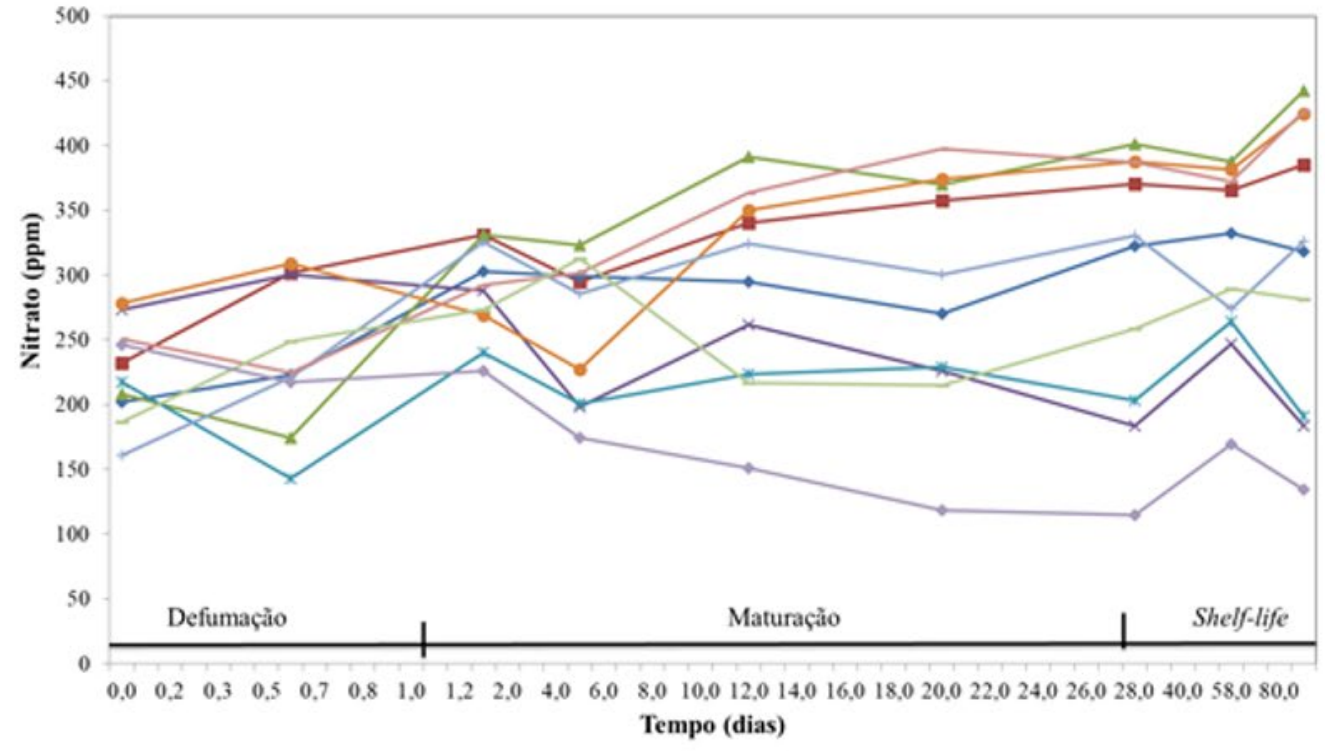

$\rightarrow$ DBR $\rightarrow-\mathrm{DBR} 2$ $\mp$ DBR 3

*DBR 4 $\rightarrow$ DBR $\rightarrow-$ GBR : + GBR 2 -GBR 3 GBR 4 $\multimap$ GBR 5

(a)

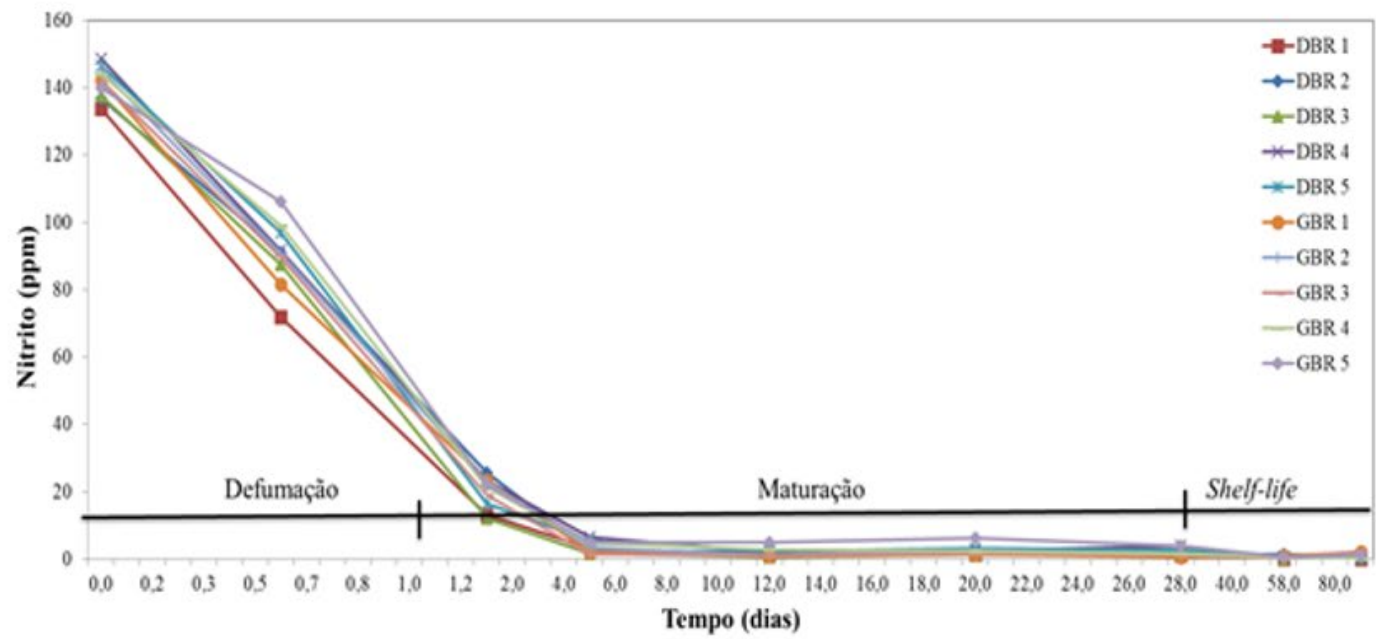

(b)

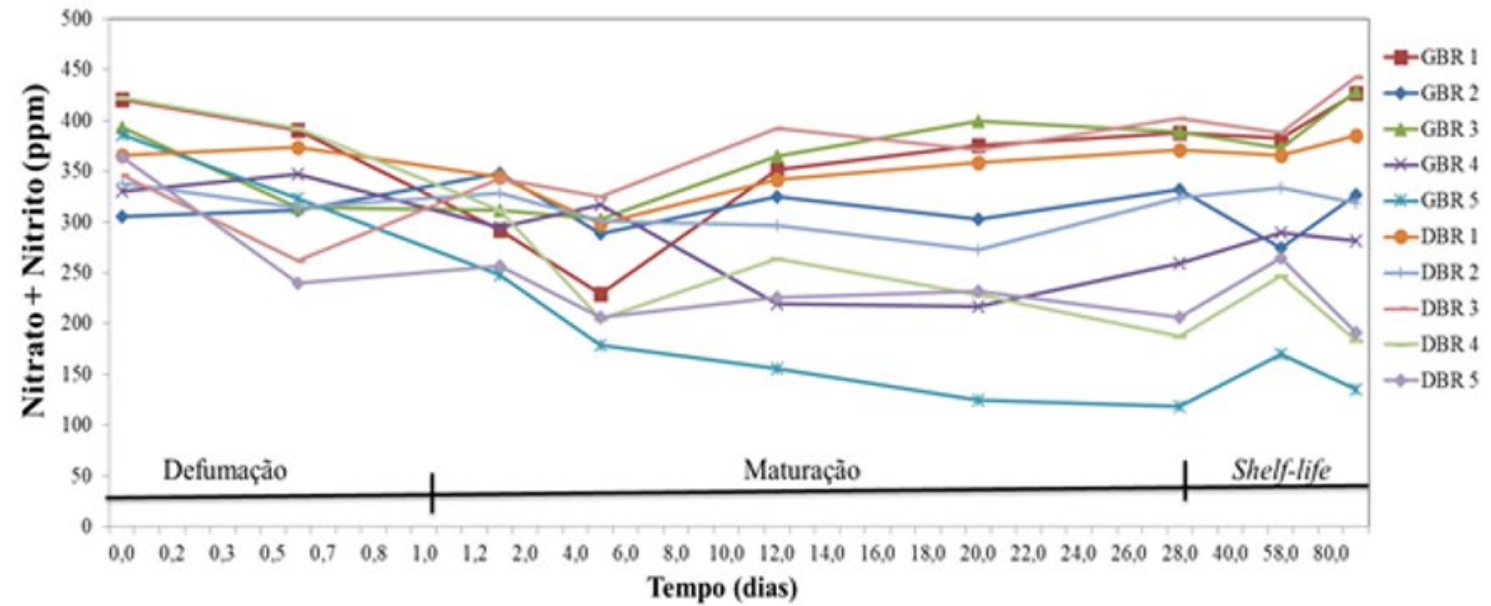

Figura 3: Valores de nitrato (a), nitrito (b), e soma de nitrato + nitrito (c) das formulações de Salame Tipo Italiano durante a defumação, maturação e shelf life. 
Tabela 7. Valores de umidade nos Salames Tipo Italiano com diferentes culturas starters e diferentes concentrações de substrato durante a defumação

\begin{tabular}{|c|c|c|c|c|c|}
\hline \multirow{2}{*}{ Tempo (h) } & \multicolumn{5}{|c|}{ Umidade (g/100g) } \\
\hline & DBRl & DBR2 & DBR3 & DBR4 & DBR5 \\
\hline 0 & $59,93^{\mathrm{d}, \mathrm{A}} \pm 0,07$ & $62,12^{\mathrm{a}, \mathrm{A}} \pm 0,06$ & $60,66^{\mathrm{c}, \mathrm{B}} \pm 0,07$ & $60,94^{b, B} \pm 0,03$ & $60,74^{\mathrm{c}, \mathrm{B}} \pm 0,09$ \\
\hline 30 & $57,24 \mathrm{e}, \mathrm{A}=0,03$ & $57,78^{\mathrm{d}, \mathrm{B}} \pm 0,04$ & $59,61^{\mathrm{a}, \mathrm{A}} \pm 0,01$ & $59,19 \mathrm{~b}, \mathrm{~A} \pm 0,03$ & $59,13 c, A \pm 0,01$ \\
\hline & GBRl & GBR2 & GBR3 & GBR4 & GBR5 \\
\hline 0 & $58,27^{\mathrm{d}, \mathrm{B}} \pm 0,07$ & $60,46^{c, B} \pm 0,06$ & $61,55^{b, A} \pm 0,02$ & $61,57^{b}, A \pm 0,09$ & $62,67^{\mathrm{a}, \mathrm{A}} \pm 0,04$ \\
\hline 30 & $56,89 \mathrm{~d}, \mathrm{~B}=0,02$ & $58,15 \mathrm{c}, \mathrm{A}=0,01$ & $58,85^{a b, B} \pm 0,03$ & $59,31^{\mathrm{a}, \mathrm{A}} \pm 0,06$ & $59,70^{\mathrm{b}, \mathrm{A}} \pm 0,29$ \\
\hline
\end{tabular}

Fonte: Elaboração própria. Média (três repetições) $=$ Desvio Padrão seguidas de letras minúsculas iguais nas linhas indicam não haver diferença significativa em nível de $5 \%$ (teste de Tukey) e maiúsculas iguais na coluna no mesmo dia de análise indicam não haver diferença significativa em nivel de $5 \%$ ( $(T$-student $)$.

As análises de umidade durante a maturação foram realizadas no $12^{\circ}, 20^{\circ}$ e $28^{\circ}$ dia (Tabela 8). Foi possível verificar que houve diferença significativa $(p<0,05)$ entre as concentrações dos substratos para a umidade no produto usando as culturas 2 e 3 . Nas culturas 1 e 5 , foi observada diferença no $12^{\circ}$ dia, e na cultura 4 no último dia de análise (28 dias).

Verifica-se que houve diferença significativa $(\mathrm{p}<0,05)$ na umidade entre as amostras com diferentes culturas utilizando 99,5\% de substrato após 28 dias de maturação (entre 35,65 e 38,28\%). Nos experimentos utilizando $40,5 \%$ de substrato, observou-se diferenças significativas $(p<0,05)$ entre as culturas em todos os tempos avaliados, sendo que os maiores valores de umidade foram observados nas culturas 2 e 3 (37,10 e 36,90\%, respectivamente) após 28 dias de maturação. Foram observadas reduções nos valores de umidade em todas as culturas em ambas as concentrações do substrato durante o período de maturação (28 dias) com valores próximos aos recomendados para Salame tipo Italiano (até $35 \%)^{(30)}$ (Tabela 8).

Tabela 8. Valores de umidade do Salame Tipo Italiano com diferentes culturas starters e diferentes concentrações de substrato durante a maturação

\begin{tabular}{|c|c|c|c|c|c|}
\hline \multirow{2}{*}{ Tempo (dias) } & \multicolumn{5}{|c|}{ Umidade $(\mathrm{g} / 100 \mathrm{~g})$} \\
\hline & DBRl & DBR2 & DBR3 & DBR4 & DBR5 \\
\hline 12 & $46,17^{\mathrm{a}, \mathrm{A}} \pm 0,30$ & $46,60^{2, B} \pm 0,40$ & $46,61^{a, A} \pm 0,40$ & $46,82^{a, A} \pm 0,30$ & $46,12^{\mathrm{a}, \mathrm{B}} \pm 0,18$ \\
\hline 20 & $41,25^{\mathrm{a}, \mathrm{A}} \pm 0,26$ & $41,61^{2, B} \pm 0,26$ & $41,95^{\mathrm{a}, \mathrm{A}} \pm 0,41$ & $41,57^{\mathrm{a}, \mathrm{A}} \pm 0,33$ & $40,71^{\mathrm{a}, \mathrm{A}} \pm 0,32$ \\
\hline 28 & $36,68^{\mathrm{c} A} \pm 0,10$ & $36,64^{\mathrm{c}, \mathrm{B}} \pm 0,16$ & $37,29^{\mathrm{bA \lambda}} \pm 0,19$ & $38,28^{\mathrm{a} A \mathrm{~A}} \pm 0,11$ & $35,65^{\mathrm{d}, \mathrm{A}} \pm 0,17$ \\
\hline & GBRl & GBR2 & GBR3 & GBR4 & GBR5 \\
\hline 12 & $45,18^{\mathrm{d}, \mathrm{B}} \pm 0,16$ & $45,99^{\circ, A} \pm 0,28$ & $47,58^{2, B} \pm 0,14$ & $46,90^{\mathrm{b}, \mathrm{A}} \pm 0,13$ & $46,74^{\mathrm{b}, \mathrm{A}} \pm 0,19$ \\
\hline 20 & $41,27^{\mathrm{b}, \mathrm{A}} \pm 0,10$ & $42,38^{\mathrm{a}, \mathrm{A}} \pm 0,06$ & $40,99^{\mathrm{bc}, \mathrm{B}} \pm 0,11$ & $41,16^{\mathrm{b} \lambda} \pm 0,11$ & $40,57^{\mathrm{c}, \mathrm{A}} \pm 0,26$ \\
\hline 28 & $36,67^{\mathrm{b} A \mathrm{~A}} \pm 0,17$ & $37,10^{\mathrm{a}, \mathrm{A}} \pm 0,04$ & $36,90^{2 b, B} \pm 0,16$ & $36,33^{\mathrm{b}, \mathrm{B}} \pm 0,18$ & $35,85^{\mathrm{c}, \mathrm{A}} \pm 0,13$ \\
\hline
\end{tabular}

Fonte: Elaboração própria. Média (três repetições) \pm Desvio Padrão seguidas de letras minúsculas iguais na linha indicam não haver diferença significativa em nivel de $5 \%$ (teste de Tukey) e maiúsculas iguais na coluna no mesmo dia de análise indicam não haver diferença significativa em nível de $5 \%$ ( $(T$-student).

Valores de umidade de $40,85 \%, 41,47 \%, 41,48 \%$ e $38,54 \%$ foram obtidos para quatro tratamentos em estudo realizado por Macedo ${ }^{(31)}$, que variaram quanto ao tipo da cultura bacteriana adicionada ao embutido cárneo, fermentados após 25 dias de maturação. O Tratamento 1, denominado de tratamento controle, recebeu adição apenas da cultura starter comercial, enquanto que nos demais tratamentos, os embutidos receberam, além da cultura starter, a adição de diferentes espécies de Lactobacillus potencialmente probióticos, de acordo com a seguinte descrição: Tratamento 1 (controle): cultura 
starter TSPX contendo Pediococcus pentosaceus e S. xylosus; Tratamento 2: cultura starter TSPX + cultura pura de L. casei; Tratamento 3: cultura starter TSPX + cultura pura de L. casei ssp. rhamnosus; Tratamento 4: cultura starter TSPX + cultura pura de L. paracasei ssp. paracasei.

Culturas starters mistas selecionadas de L. sakei $487+$ S. vitulinus C2 (S1) e L. sakei $442+$ S. xylosus (S2) foram avaliadas na fabricação artesanal de embutido fermentado (Argentina) ${ }^{(32)}$. Os autores verificaram valores de umidade no final do período de maturação (15 dias) de 27,58 e 32,41\% com as culturas $\mathrm{S} 1$ e S2, respectivamente. No entanto, esses valores foram consideravelmente mais baixos do que os encontrados no presente estudo, que tem como diferença a região em que foram produzidos e o tempo de cura menor.

Os resultados da umidade das amostras de salame na fase shelf life (Tabela 9) mostraram que houve diferença significativa, em nível de $95 \%$, entre as concentrações do substrato em 88 dias para a cultura 1, em 28 e 88 dias para a cultura 2 e 3 , em 28,58 e 88 dias para a cultura 4 e 5.

Comparando as culturas, em 88 dias de shelf life, as amostras contendo $99,5 \%$ de substrato diferiram significativamente $(\mathrm{p}<0,05)$, com valores de umidade que variaram de 34,52 a 37,25\%. No caso do uso de $40,5 \%$ de substrato, não houve diferença $(\mathrm{p}>0,05)$ entre as culturas com 88 dias de shelf life, com umidade máxima de 36,86\% (Tabela 9).

Tabela 9. Valores de umidade do Salame Tipo Italiano obtido com diferentes culturas starters e
concentrações de substrato durante o shelf life

\begin{tabular}{|c|c|c|c|c|c|}
\hline \multirow{2}{*}{ Tempo (dias) } & \multicolumn{5}{|c|}{ Umidade (g/100g) } \\
\hline & DBRI & DBR2 & DBR3 & DBR4 & DBR5 \\
\hline 28 & $36,68^{\mathrm{c}, A} \pm 0,01$ & $36,64^{\mathrm{c}, A} \pm 0,06$ & $37,29 \mathrm{bAa} \pm 0,09$ & $38,28^{\mathrm{a}, \mathrm{A}} \pm 0,01$ & $35,67^{\mathrm{d}, \mathrm{B}} \pm 0,07$ \\
\hline 58 & $35,35^{\mathrm{c}, A} \pm 0,01$ & $34,55^{\mathrm{d}, \mathrm{B}} \pm 0,04$ & $35,73^{\mathrm{bAa}} \pm 0,06$ & $36,02^{\mathrm{a}, \mathrm{A}} \pm 0,08$ & $35,98^{\mathrm{a}, \mathrm{B}} \pm 0,08$ \\
\hline 88 & $34,52^{\mathrm{e}, \mathrm{B}} \pm 0,01$ & $35,52^{\mathrm{c}, A} \pm 0,01$ & $36,10^{\mathrm{b}, \mathrm{A}} \pm 0,01$ & $37,25^{\mathrm{a}, \mathrm{A}} \pm 0,04$ & $35,28^{\mathrm{d}, \mathrm{B}} \pm 0,08$ \\
\hline & GBRI & GBR2 & GBR3 & GBR4 & GBR5 \\
\hline 28 & $36,67^{\mathrm{b}, \mathrm{A}} \pm 0,07$ & $37,10^{a, A} \pm 0,04$ & $36,90^{\mathrm{ab}, \mathrm{A}} \pm 0,06$ & $36,33^{\mathrm{c}, \mathrm{B}} \pm 0,08$ & $35,85^{\mathrm{d}, \mathrm{A}} \pm 0,13$ \\
\hline 58 & $34,94^{\mathrm{c}, A} \pm 0,06$ & $34,95^{\mathrm{C}, \mathrm{A}} \pm 0,04$ & $35,64^{b, B} \pm 0,06$ & $35,12^{\mathrm{c}, \mathrm{B}} \pm 0,06$ & $36,68^{a, A} \pm 0,02$ \\
\hline 88 & $35,08^{\mathrm{a} A \mathrm{~A}} \pm 0,94$ & $35,39^{2, B} \pm 0,04$ & $35,35^{2, B} \pm 0,05$ & $35,08^{2, B} \pm 0,01$ & $35,86^{\mathrm{a}, \mathrm{A}} \pm 0,06$ \\
\hline
\end{tabular}

Fonte: Elaboração própria. Média (três repetições) \pm Desvio Padrão seguidas de letras minúsculas iguais na linha indicam não haver diferença significativa em nível de $5 \%$ (teste de Tukey) e maiúsculas iguais na coluna no mesmo dia de análise indicam não haver diferença significativa em nivel de $5 \%$ ( $T$-student $)$.

Os valores de atividade de água (Aw) durante a defumação, maturação e shelf life estão apresentadas na Figura 4. Verifica-se que ambas as formulações com diferentes concentrações de substrato tiveram o mesmo comportamento durante o período de maturação, em que os valores de Aw diminuíram com o passar do tempo. Após 28 dias de maturação, observou-se valores de Aw abaixo de 0,90. Dessa forma, atende-se às características de qualidade e identidade de Salame Tipo Italiano ${ }^{(28)}$. Essa redução pode ser atribuída à queda dos valores de $\mathrm{pH}$, pois a capacidade de retenção de água das proteínas da carne diminui na medida em que o $\mathrm{pH}$ se aproximava do seu ponto isoelétrico, acelerando a desidratação e, consequentemente, reduzindo a Aw. Essa redução da Aw e umidade em embutidos fermentados e defumados, caso do Salame Tipo Italiano, é muito favorável para sua estabilidade e conservação da temperatura ambiente. Além disso, essas variáveis associadas com o baixo pH e o nitrito são importantes para a segurança microbiológica. De acordo com Dalla Santa ${ }^{(33)}$, os produtos cárneos fermentados podem ser deteriorados por Clostridium, Aspergilus, Penicillium entre outros. Com valores de Aw abaixo de 0,92 as bactérias patogênicas são inibidas, com exceção do Staphylococcus aureus ${ }^{(34)}$. 


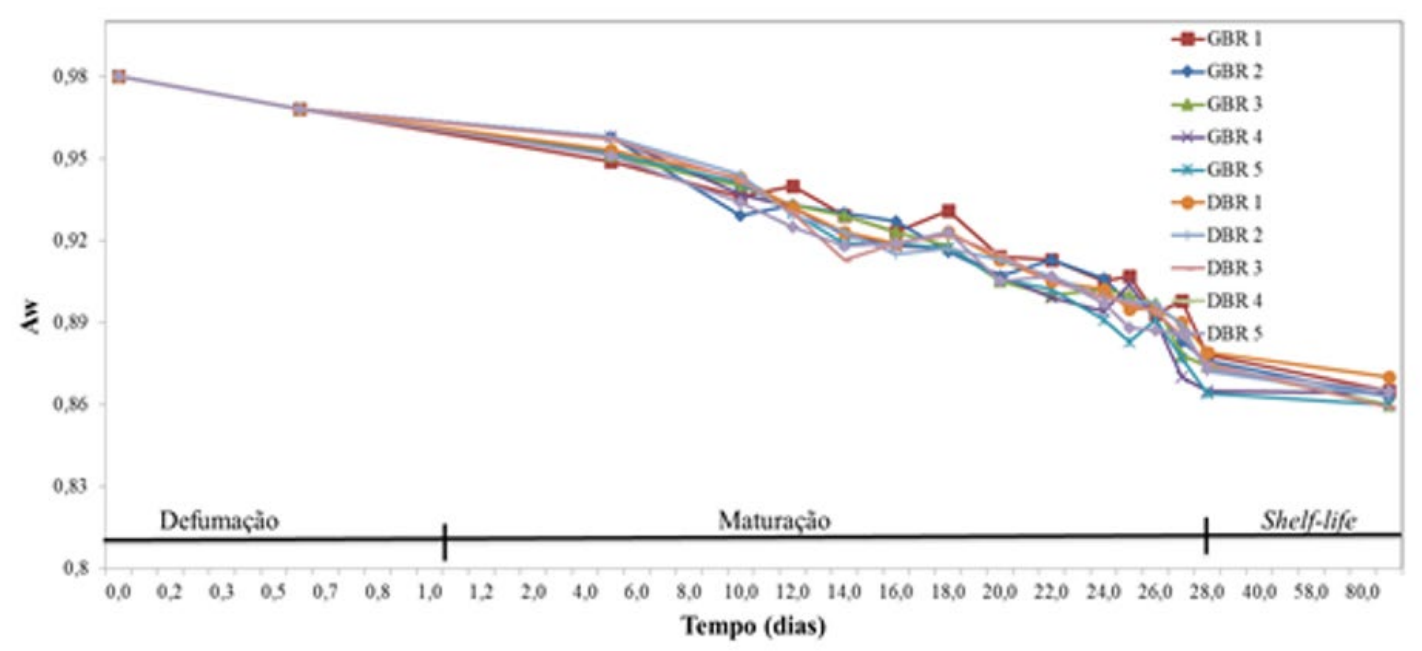

Fonte: Elaboração própria.

Figura 4. Valores de Aw das formulações de Salame Tipo Italiano durante a defumação, maturação e shelf life.

Os resultados de proteína com as diferentes culturas starters durante a defumação, maturação e shelflife das formulações de salames com diferentes concentrações de substrato não apresentaram diferença significativa $(\mathrm{p}>0,05)$ (dados não apresentados). Foi observado aumento no teor de proteínas especialmente durante a maturação do salame, tendo em vista que, com a redução de mais de $30 \%$ no teor de umidade do produto, haverá concentração de todos os nutrientes presentes. Considerando que o teor de proteína mínimo é de $25 \%$ segundo o regulamento técnico de identidade e qualidade do Salame Tipo Italiano, somente as amostras DBR1 (durante o shelf life) e GBR1 (durante todo o período avaliado) apresentaram teores de proteína abaixo do especificado. Conforme a Figura 5, o teor de proteína inicialmente foi baixo, principalmente na formulação GBR1, indicando erro de formulação e não influência dos tratamentos avaliados.

As variações dos valores encontrados de proteína durante a defumação (Figura 5) tem relação com os valores de $\mathrm{pH}$, pois sua redução minimiza as cargas elétricas, reduzindo, consequentemente, a ligação das moléculas de água às proteínas, facilitando a liberação desta ${ }^{(35)}$, resultando em menor teor umidade e maior teor de proteína com o passar do tempo de defumação, observando-se os maiores teores de proteína durante a maturação, para a maioria dos tratamentos.

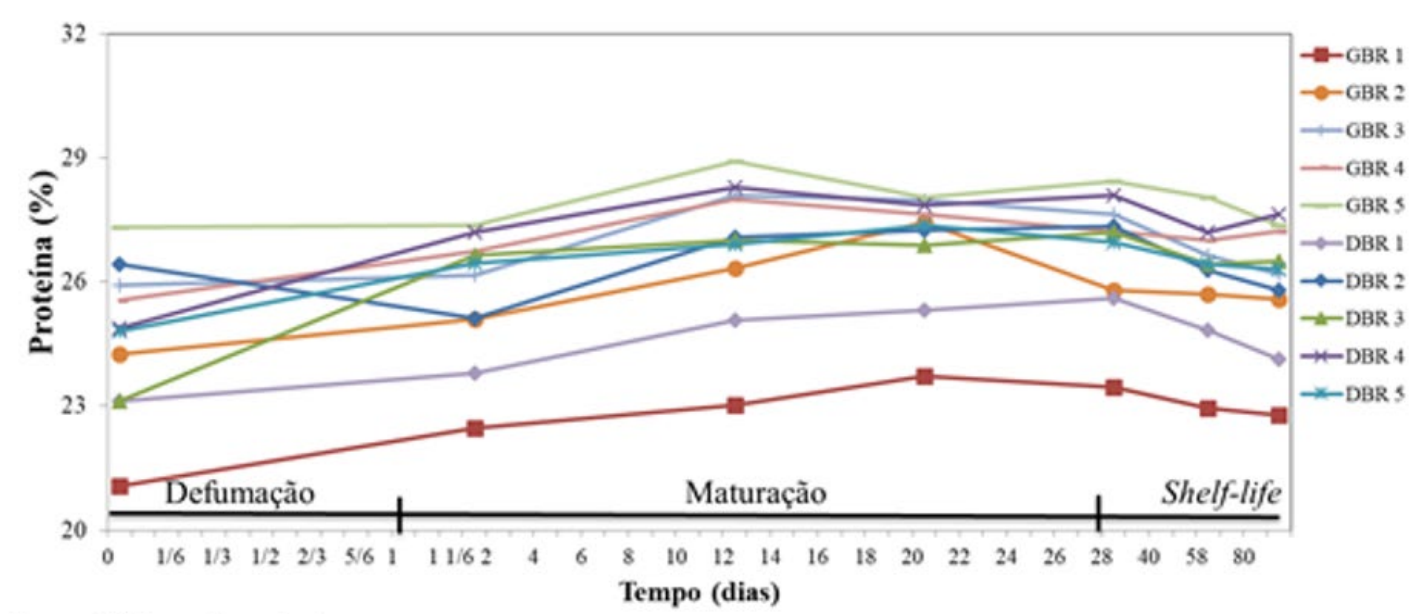

Fonte: Elaboração própria.

Figura 5. Valores de proteína (\%) das formulações de Salame Tipo Italiano durante a defumação, maturação e shelf life. 
As características finais peculiares dos salames dependem também do tipo e qualidade da carne utilizada $^{(1)}$. Não é fácil padronizar a composição química da carne, já que existem muitas diferenças devido a fatores como a espécie, a raça, o sexo, a idade, o tipo de alimentação e o corte analisado. Os componentes majoritários da carne são: água (65\%-80\%), proteína (16\%-22\%), gordura (3\%-13\%) e cinza $^{(27)}$. As proteínas da carne são os constituintes mais importantes dos salames, tanto pelo valor nutricional como pelas suas propriedades tecnológicas. As proteínas são os principais componentes funcionais e estruturais de carnes processadas. Entre suas propriedades, estão a solubilidade, a viscosidade, a ligação com a água e gordura, a coagulação e a emulsificação ${ }^{(36)}$. A degradação das proteínas em peptídeos e aminoácidos, durante o processamento dos salames, provoca alterações benéficas, contribuindo com a formação do flavour característico do produto final.

Os resultados de gordura durante a defumação, maturação e shelf life, em relação às diferentes concentrações de substrato e as culturas starters utilizadas, não apresentaram diferenças significativas ( $p>0,05$ ) nas etapas analisadas (dados não apresentados), com variações entre 24,56 a 28,38\%, mas a maioria dos tratamentos apresentou pequenas variações entre 1 e $2 \%$ (Figura 6). Esse teor de gordura durante a maturação e shelf life demonstrou uma tendência a redução devido a sua concentração, pela redução da umidade nos diferentes tratamentos. De acordo com a Instrução Normativa N. 22, de 31 de julho de $2000^{(28)}$, o Salame Tipo Italiano deve apresentar valor máximo de $32 \%$ de gordura. Desse modo, os valores obtidos no presente estudo estão de acordo com a legislação.

O teor de gordura de salames fermentados processados à maneira dos países mediterrâneos e dos países do Norte da Europa varia entre 31,9 e $42,8 \%{ }^{(37)}$. Em Salame Tipo Italiano produzido por fermentação espontânea com cultura starters (Pediococcus pentosaceus e S. xylosus), após a maturação, observou valor de gordura de $34,84 \%{ }^{(38)}$, ou melhor, valores superiores ao encontrado para o presente estudo.

A gordura é um componente utilizado na elaboração de salames, estando presente na carne ou pela utilização de gordura dorsal (toucinho). Durante o processamento e o armazenamento, uma das mais significativas alterações que ocorrem na fração lipídica é a hidrólise dos triglicerídios pelas lipases liberando ácidos graxos livres, que são muito importantes na formação do flavour característico desses $\operatorname{produtos}^{(3)}$.

As gorduras presentes nas matérias-primas utilizadas na fabricação de salames, além da importante função tecnológica de contribuir com a formação das características finais, também podem determinar a vida de prateleira do produto (shelflife). A rancificação das gorduras leva à formação de compostos que produzem alterações no flavour do produto, conferindo sabor típico de ranço. A rancificação também pode provocar o escurecimento dos salames ${ }^{(1)}$. Além da diminuição da vida de prateleira, a oxidação lipídica leva a formação de substâncias prejudiciais à saúde, como o malonaldeído capaz de causar mutações e câncer ${ }^{(39)}$.

Os resultados da dureza, adesividade, elasticidade, coesividade e mastigabilidade do salame após 60 dias de estocagem (Tabela 10) não apresentaram diferenças significativas $(\mathrm{p}>0,05)$ entre as culturas starters avaliadas utilizando a mesma concentração de substrato, com exceção da análise de coesividade utilizando 99,5\% substrato. Desse modo, verificou-se que as diferentes culturas starters estudadas não interferiram nos resultados de textura.

Na avaliação da elasticidade do salame pelo texturômetro, os resultados para cada cultura starter, variando a concentração de substrato, mostrou diferença significativa $(\mathrm{p}<0,05)$ apenas na cultura 4 e cultura 5 . Para a cultura 4, os valores encontrados foram de 0,80 para a amostra GBR4 e 0,88 para DBR4. A cultura 5 obteve valores de 0,79 para a GBR5 e 0,85 para a DBR5. 


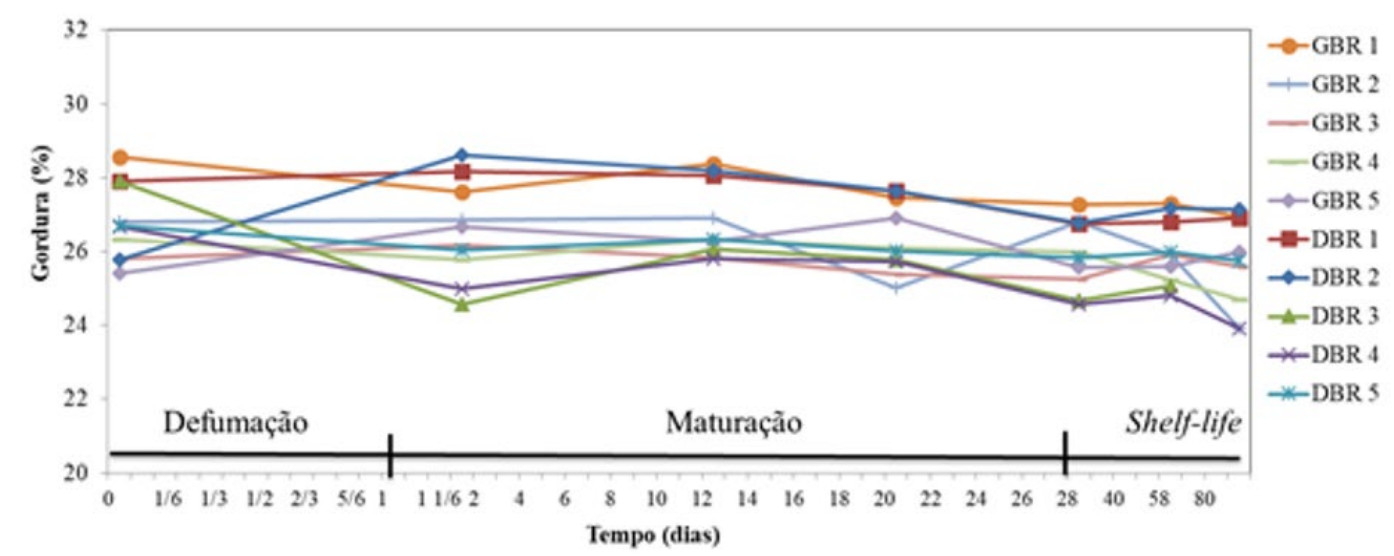

Fonte: Elaboração própria.

Figura 6. Valores de gordura (\%) das formulações de Salame Tipo Italiano durante a defumação, maturação e shelf life.

Os resultados da coesividade do salame obtidos pelo texturômetro para cada cultura starter, comparando a concentração de substrato, mostraram que houve diferença significativa $(\mathrm{p}<0,05)$ entre a concentração do substrato (40,5 e 99,5\%) para a cultura 2, com valores de coesividade de 0,68 e 0,70 com 40,5 e 99,5\% de substrato, respectivamente. A coesividade é uma medida do grau de dificuldade em quebrar a estrutura interna dos salames, dessa forma verifica-se que não houve diferença significativa entre a estrutura das amostras de salame estudadas.

Em relação à mastigabilidade do Salame Tipo Italiano avaliada pelo texturômetro, os resultados mostraram que não houve diferença $(\mathrm{p}>0,05)$ para as culturas starters e concentração substrato. Em salsichas de porco cozidas, observou-se menores valores de coesividade $(0,57)$ e mastigabilidade $(4303)^{(40)}$ que o presente estudo em Salame Tipo Italiano, em que essas diferenças podem estar associadas às propriedades de ligação da água e ao cozimento do produto.

Esses parâmetros de textura são de controle interno das indústrias, sendo as faixas ótimas estabelecidas para cada fabricante, dando identidade a marca do produto.

Tabela 10. Respostas da análise de textura no Salame Tipo Italiano após 60 dias de estocagem

\begin{tabular}{|c|c|c|c|c|c|}
\hline \multirow{2}{*}{ Textura } & \multicolumn{5}{|c|}{ Formulações } \\
\hline & DBRl & DBR2 & DBR3 & DBR4 & DBR5 \\
\hline Dureza & $10113^{a, A} \pm 721$ & $9916^{24} \pm 374$ & $10809^{\mathrm{a}, \Lambda} \pm 974$ & $10182^{\mathrm{a}, \AA} \pm 290$ & $10966^{\mathrm{a}, \mathrm{A}} \pm 684$ \\
\hline Adesividade & $-102^{a, A} \pm 39$ & $-80^{\mathrm{a} A} \pm 44$ & $-153^{\mathrm{aA} A} \pm 42$ & $-85^{\mathrm{a}, \mathrm{A}} \pm 51$ & $-102^{\mathrm{a}, \mathrm{A}} \pm 25$ \\
\hline Elasticidade & $0,839^{\mathrm{a}, \mathrm{A}} \pm 0,04$ & $0,849^{2, \lambda} \pm 0,02$ & $0,803^{2 \lambda} \pm 0,04$ & $0,885^{2 A} \pm 0,02$ & $0,854^{2 \lambda} \pm 0,02$ \\
\hline Coesividade & $0,686^{\mathrm{a}, \mathrm{A}} \pm 0,03$ & $0,700^{2 \lambda} \pm 0,01$ & $0,683^{2 A} \pm 0,02$ & $0,679^{2 A} \pm 0,01$ & $0,685^{2 A} \pm 0,01$ \\
\hline \multirow[t]{2}{*}{ Mastigabilidade } & $5844^{\mathrm{a}, \mathrm{A}}=859^{2}$ & $5890^{\mathrm{a}, \mathrm{A}} \pm 84$ & $5926^{\mathrm{a}, A} \pm 595$ & $6119^{\mathrm{a}, A} \pm 170$ & $6421^{\mathrm{a}, \mathrm{A}} \pm 415^{2}$ \\
\hline & GBRl & GBR2 & GBR3 & GBR4 & GBR5 \\
\hline Dureza & $9453^{\mathrm{a}, \mathrm{A}} \pm 838$ & $10463^{24} \pm 1174$ & $11311^{2 \lambda} \pm 1046$ & $11200^{24} \pm 1256$ & $11287^{2 A} \pm 1168$ \\
\hline Adesividade & $-24^{\mathrm{a}, \mathrm{A}} \pm 7$ & $-82^{a, A} \pm 79$ & $-125^{2, A} \pm 32$ & $-85^{\mathrm{a}, \mathrm{A}} \pm 88$ & $-138^{\mathrm{a}, \mathrm{A}} \pm 61$ \\
\hline Elasticidade & $0,824^{\mathrm{ab}, \lambda} \pm 0,03$ & $0,839^{a b, A} \pm 0,02$ & $0,830^{\mathrm{b}, \mathrm{B}} \pm 0,01$ & $0,797^{a, B} \pm 0,03$ & $0,793^{\mathrm{ab}, \mathrm{B}} \pm 0,01$ \\
\hline Coesividade & $0,684^{\mathrm{a}, \mathrm{A}} \pm 0,02$ & $0,676^{\mathrm{a}, \mathrm{B}} \pm 0,01$ & $0,689^{2,1} \pm 0,01$ & $0,694^{24} \pm 0,01$ & $0,676^{2 \lambda} \pm 0,01$ \\
\hline Mastigabilidade & $5316^{\mathrm{a}, \mathrm{A}} \pm 263$ & $5924^{\mathrm{a}, \mathrm{A}} \pm 510$ & $6466^{\mathrm{a}, \mathrm{A}} \pm 564$ & $6186^{24} \pm 648$ & $6059^{\mathrm{a}, \mathrm{A}} \pm 697$ \\
\hline Fonte: Elaboração & 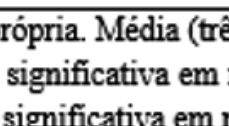 & 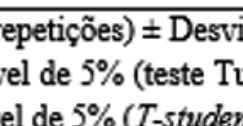 & & & \\
\hline
\end{tabular}

Todas as formulações de salames após 60 dias de shelf life foram avaliadas microbiologicamente e 
apresentaram valores abaixo de $1,0 \times 10 \mathrm{UFC} / \mathrm{g}$ para os coliformes termotolerantes e $S$. coagulase positiva. Para a L. monocytogenes e Salmonella sp., todas as análises apresentaram ausência de contagem. Desse modo, demonstraram que não houve crescimento de micro-organismos patogênicos em todas as amostras estudadas.

Com a finalidade de evitar riscos à saúde do consumidor, a legislação brasileira ${ }^{(28)}$ estabelece padrões microbiológicos sanitários para produtos cárneos maturados (salames) de: coliformes a $45^{\circ} \mathrm{C}$, a tolerância para a amostra indicativa e para cada uma das duas amostras em cinco analisadas é de $10^{3} \mathrm{UFC} / \mathrm{g} ; S$. coagulase positiva, a tolerância para a amostra indicativa é para uma amostra em cinco analisadas de 5,0 × $10^{3} \mathrm{UFC} / \mathrm{g}$; Salmonella sp. deve estar ausente tanto na amostra indicativa quanto nas cinco amostras analisadas. Dessa forma, todas as amostras analisadas encontram-se de acordo com os valores preconizados pela legislação. Os coliformes não crescem bem em pH baixo, apresentando superioridade competitiva das bactérias láticas sobre a microbiota endógena, isso pode ocorrer em produtos cárneos fermentados com adição de culturas iniciadoras e produzidas por fermentação espontânea ${ }^{(38,41)}$.

A Figura 7 apresenta a contagem de bactérias lácticas nas amostras durante a maturação e shelf life (estocagem por 60 dias), em que verifica-se valores crescentes durante a defumação, constantes com algumas flutuações durante a maturação, com posterior redução durante o processo de estocagem.

No período de defumação, a maior parte dos açúcares está sendo fermentada, com maior liberação de ácido láctico, porém esse processo de crescimento exponencial pode se estender por um pouco mais de tempo, durante os primeiros dias de maturação, tendo as culturas BR3 e BR4 apresentando comportamentos diferenciados, em relação às demais culturas testadas.

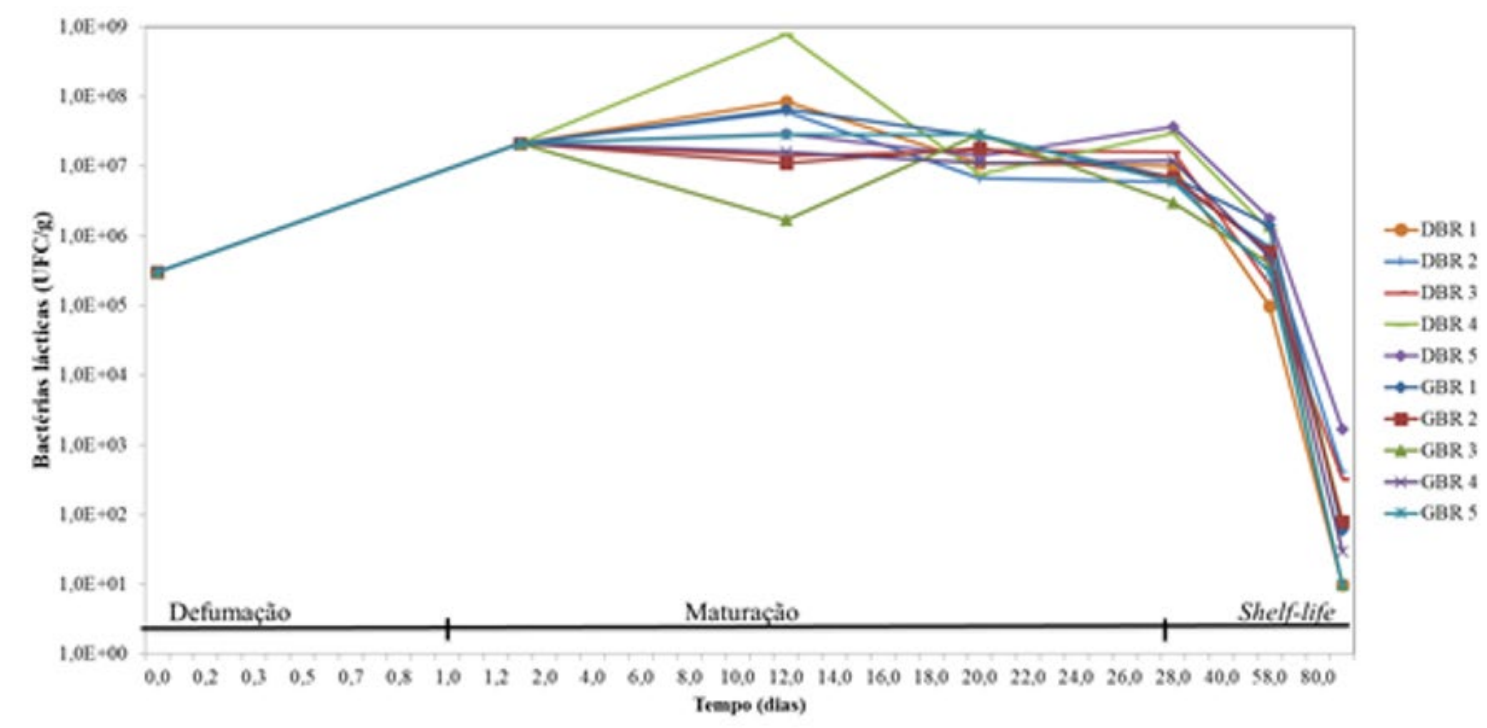

Fonte: Elaboração própria.

Figura 7. Contagem de bactérias lácticas (UFC/g) das formulações de Salame Tipo Italiano durante a fermentação, maturação e shelf life.

A temperatura de maturação afeta significativamente a concentração final de Micrococcaceae. Em estudo realizado avaliando o efeito das condições de processamento sobre salame turco, durante o período de fermentação, a temperatura de $24-26{ }^{\circ} \mathrm{C}$, a concentração foi de aproximadamente 7 $\log \mathrm{UFC} / \mathrm{g}$, já a $22-24{ }^{\circ} \mathrm{C}$ a contagem ficou abaixo de $6 \mathrm{log} \mathrm{UFC} / \mathrm{g}^{(42)}$. O baixo número de Micrococcaceae durante o processamento de salames fermentados ou a diminuição da concentração 
no período de maturação pode ser devido à inibição causada pela diminuição acentuada do $\mathrm{pH}^{(42)}$, ocasionado pelo desenvolvimento das bactérias lácticas.

As bactérias lácticas compõem a microbiota predominante em embutidos fermentados, devido às condições anaeróbicas do meio e presença de cloreto de sódio, nitrato e nitrito, alcançando uma contagem de 7-8 $\log \mathrm{UFC} / \mathrm{g}$, após 3 dias de fermentação, mantendo-se estável durante a fermentação ${ }^{(43)}$. No presente trabalho, verificou-se no início de fabricação uma contagem de aproximadamente 5,5 log UFC/g. Após a fermentação, iniciando a maturação (3 dias), as amostras apresentaram contagens de aproximadamente 7,0 $\log \mathrm{UFC} / \mathrm{g}$, diminuindo muito pouco até o final da maturação.

Durante o shelf life, observa-se uma redução significativa das bactérias ácido-lácticas, principalmente nos últimos 30 dias, sendo esse um comportamento normal daqueles micro-organismos, visto que a concentração de oxigênio é um fator limitante no seu desenvolvimento.

$\mathrm{Na}$ análise sensorial dos salames com as diferentes culturas e com a menor concentração de substrato (40,5\%), Figura 8, em relação ao atributo odor, as amostras DBR4 e DBR5 foram melhor avaliadas e receberam a mesma nota $(3,45)$, sendo que os resultados ficaram muito próximos. Porém, nas amostras com maior concentração de substrato $(99,5 \%)$ em relação ao atributo odor, a amostra GBR5 apresentou a melhor aceitação, sendo classificada como "muito bom".

Quanto ao atributo acidez, as amostras DBR4 e GBR4 foram classificadas como as mais ácidas entre as avaliadas, e a DBR1, GBR1 e GBR5 como menos ácidas. O resultado sensorial de acidez pode estar relacionado aos valores de pH no final da maturação, sendo as amostras GBR1 e GBR5 com os menores valores de $\mathrm{pH}$, ou seja, 5,21 e 5,19, respectivamente. Embora alguns fatores como, por exemplo, efeito tampão de algumas substâncias, podem influenciar no pH de um alimento, fazendo com que esta variável apresente valores mais altos do que teria se não houvessem no meio substâncias sequestradoras de $\mathrm{H}^{+}$.

$\mathrm{Na}$ avaliação do atributo sabor, as amostras DBR1, DBR2 e GBR5 foram as mais aceitas pelos degustadores, sendo classificadas como "bom", e as amostras DBR3, GBR1 e GBR2 foram as menos aceitas pelos degustadores.

Quanto ao atributo cor, as amostras DBR5 e GBR5 receberam as melhores notas para o atributo, sendo classificadas entre "bom" e "muito bom", podendo estar relacionadas aos menores teores de nitrato + nitrito, principalmente da amostra GBR5.

Em relação à textura, as amostras DBR1, DBR2, GBR5 foram classificadas pelos degustadores com a melhor textura. A amostra DBR3 apresentou a menor nota para o atributo sensorial, corroborando o resultado obtido com o equipamento texturômetro, no qual a amostra apresentou menor adesividade e elasticidade.

Quanto ao atributo amargo, os degustadores classificaram as amostras DBR4 e GBR1 com maior amargor e as DBR1, GBR3 e GBR4 com menor amargor.

$\mathrm{Na}$ avaliação geral, as amostras com menor concentração de substrato (40,5\%) não apresentaram diferença $(p>0,05)$ para os provadores. Contudo, a formulação GBR5 com maior concentração substrato $(99,5 \%)$ recebeu as maiores notas e foi mais bem aceita pelos degustadores. 


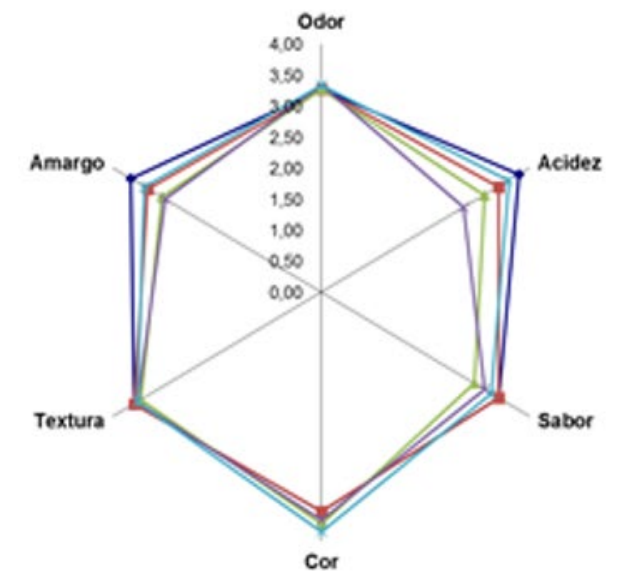

(a)

Fonte: Elaboração própria

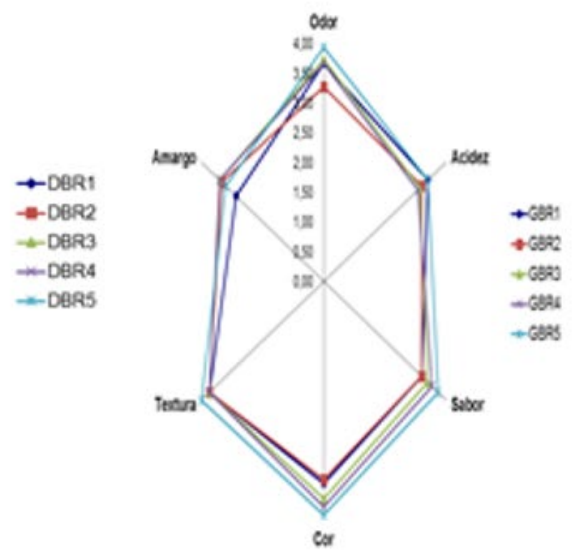

(b)

Figura 8. Atributos sensoriais (odor, sabor, cor, textura, acidez e amargor) do Salame Tipo Italiano com diferentes culturas starters e diferentes concentrações de substrato após 60 dias de shelf life.

\section{Conclusão}

Neste trabalho, verificou-se que o Salame Tipo Italiano obtido com diferentes culturas starter e diferentes concentrações de substrato (40,5 e 99,5\%) apresentou comportamento similar em relação $\mathrm{pH}$, umidade, proteínas e lipídios. As diferentes culturas starters utilizadas nas formulações dos salames não apresentaram interferência nos resultados de textura (dureza, adesividade, elasticidade, coesividade e mastigabilidade).

Os resultados das análises microbiológicas mostraram que os produtos das formulações estavam de acordo com a legislação específica para todas as culturas starters e diferentes concentrações de substrato (40,5 e 99,5\%) analisadas com valores de Aw abaixo de 0,9 contribuíram para o shelf life do produto.

Embora as culturas starters sejam utilizadas rotineiramente pelas indústrias processadoras de embutidos cárneos fermentados, ainda não se conhecem os detalhes da interação entre a cultura selecionada e as características desejadas em cada alimento. Com isso, este trabalho mostrou que devem ser estudados profundamente os aspectos físico-químicos e sensoriais para a escolha de uma cultura starter. Assim, para o Salame Tipo Italiano, a formulação GBR5 (com cultura starter - $S$. carnosus e L. sakei e menor concentração de substrato de glicose) foi a que atendeu os limites estabelecidos pela legislação apresentando boa aceitação sensorial.

\section{Agradecimentos}

Os autores agradecem ao Programa de Pós-Graduação em Engenharia de Alimentos da URI Erechim, CAPES (Coordenação de Aperfeiçoamento de Pessoal de Nível Superior), CNPq (Conselho Nacional 
de desenvolvimento Científico e Tecnológico) e FAPERGS (Fundação de Amparo à Pesquisa do Estado do RS) pelo auxílio financeiro.

\section{Referências}

1. Terra, N. N. Apontamentos de tecnologia de carnes. São Leopoldo: Ed. UNISSINOS, 1998.

2. Essid I. Characterization and technological properties of Staphylococcus xylosus strains from a Tunisian traditional salted meat. Meat Sci. 2007; 77 (2): 204-212.

3. Tabanelli G, Coloretti F, Chiavari C, Grazia L; Lanciotti R; Gardini, F. Effects of starter cultures and fermentation climate on the properties of two types of typical Italian dry fermented sausages produced under industrial conditions. Food Control. 2012; 26: 416-426.

4. Zanardi E, Ghidini S, Conter M, Ianieri A. Mineral composition of Italian salami and effect of $\mathrm{NaCl}$ partial replacement on compositional, physico-chemical and sensory parameters. Meat Sci. 2010; 86 (3): 742-747.

5. Pisacane V, Callegari ML, Puglisi E, Dallolio G, Rebecchi A. Microbial analyses of traditional Italian salami reveal microorganisms transfer from the natural casing to the meat matrix. Int. J. Food Microbiol. 2015; 207: $57-65$.

6. Buckenhüskes HJ. Selection criteria for lactic acid bacteria to be used as starter cultures for various food commodities. FEMS Microbiol Rev. 1993; 12: 253-272.

7. Terra AB, Fries LLM, Terra N. Particularidades na fabricação de salame. 1. ed. São Paulo: Livraria Varela, 2004; $152 \mathrm{p}$.

8. Gøtterup J, Olsen K, Knøchel S, Tjener K, Stahnke LH, Møller JKS. Colour formation in fermented sausages by meat-associated staphylococci with different nitrite- and nitrate-reductase activities, Meat Sci. 2008; 78(4): 492-501.

9. Cirolini AF, Leadir LM, Terra NN, Milani LIG, Urnau D, Santos BA, Cervo GD, Rezer APS. Salame tipo italiano elaborado com culturas starters nativas. Food Sci. Technol. 2010; 30: 171-179.

10. Marianski S, Mariański A. The art of making fermented sausages. Bookmagic LLC, 2009, 262 p.

11. AOAC. Official methods of analysis of the Association of Official Analytical Chemists. 15. ed. Washington, 1990.

12. LMO - ALIM. Metodologia vidas para detecção de Listeria monocytogenes para amostras de alimentos $\mathrm{AOAC}^{\circ} 2004.02$ e ofício circular no 2 MICRO/CGAL/2010 de 26/04/2010, métodos alternativos aprovados - MAPA, Brasil. Confirmações: ISO 11290-1:1996 - Microbiology of food and animal feeding stuffs Horizontal method for the detection and enumeration of Listeria monocytogenes (temperatura de incubação dos ágares ALOA e PALCAN $37^{\circ} \mathrm{C}$ ).

13. MDS-SLM. Metodologia MDS Salmonella spp. para amostras de alimentos - AOAC no 2013.09 e ofício circular no 8 CGAL/SDA de 02/07/2013 Métodos alternativos aprovados - MAPA, Brasil.

14. PETRI - CC. Placas petrifilm para contagem de Coliformes - AOAC n ${ }^{\circ} 991.14$, NORD VAL N ${ }^{\circ}$ 2003-205408-00011 e ofício circular $02 \mathrm{MICRO/CGAL/2010} \mathrm{DE} \mathrm{26/04/2010,} \mathrm{métodos} \mathrm{alternativos} \mathrm{aprovados} \mathrm{-}$ MAPA, Brasil.

15. PETRI - STX. Placas petrifilm para contagem de Staphylococcus-AOAC no 2003.07 e AOAC 2003.11 e ofício circular $\mathrm{n}^{\circ} 06 \mathrm{GABI} / \mathrm{CGAL} / 2012$ de 14/02/2012, métodos alternativos aprovados - MAPA, Brasil.

16. American Public Health (APHA). Compendium for the Microbiological Examination of Foods. Washington, DC: American Public Health, 2015. 
17. Associação Brasileira de normas Técnicas. NBR 14141: Escalas utilizadas em análise sensorial de alimentos e bebidas. Rio de Janeiro, 1998.

18. Bacus J. Update: meat fermentation. Food Technol. 1984; 38 (6): 59- 69.

19. Fernández M, Ordóñez JA, Bruna JM, Herranz B, Hoz L. Accelerated ripening of dry fermented sausages. Trends Food Sci. Technol. 2000; 11: 201-209.

20. Martins, R. Dossiê técnico: Produção de embutidos Crus-Curados (Salame) Redetec: p.11, julho, 2006.

21. Cavenaghi AD, Oliveira MN. Influência de algumas características físico-químicas e sensoriais na qualidade de salame tipo italiano fabricado no Brasil. Rev. Nacional da Carne, 1999; 263: 44-48.

22. Cocconcelli PS, Fontana C. Starter cultures for meat fermentation. F. Toldrà (Ed.), Handbook of Meat Processing, Blackwell Publishing, Ames, Iowa, USA, 2010; p. 199-218.

23. Ambrosiadis J, Soultos N, Abrahim A, Bloukas JG. Physicochemical, microbiological and sensory attributes for the characterization of greek traditional sausages. Meat Sci. 2004; 66 (2): 279-287.

24. Mauriello G, Casaburi A, Blaiotta G, Villani F. Isolation and technological properties of coagulase negative staphylococci from fermented sausages of southern Italy. Meat Sci. 2004; 67 (1): 149-158.

25. Casaburi A, Aristoy M-C, Cavella S, Monaco RD, Ercolini D, Toldrá F, Villani F. Biochemical and sensory characteristics of tradicional fermented sausages of Vallo di Diano (southern Italy) as affected by the use of starter cultures. Meat Sci. 2007; 76 (2): 295-307.

26. Sunesen LO, Stahnke LH. Mould starter cultures for dry sausages-selection, application and effects. Meat Sci. 2003; 65 (3): 935-948.

27. Ordóñez JA, Rodríguez MIC, Álvarez LF, Sanz MLG, Minguillón GDGF, Peralez LH, Contecero MDS. Tecnologia de alimentos. (2th ed.). Porto Alegre: Artmed, 2005.

28. BRASIL. Instrução Normativa $N^{\circ} 22$, de 31 de julho de 2000. Regulamentos técnicos de identidade e qualidade de salame tipo Italiano. Publicada no Diário oficial da União de 3/08/00. 2000.

29. BRASIL. Ministério da Agricultura, Pecuária e Abastecimento - MAPA. Instrução Normativa nº 51, de 29 de dezembro de 2006.

30. Sebranek JG, Bacus J. Natural and organic cured meat products: regulatory, manufacturing. Marketing, quality and safety issues. American Meat Sci. Ass. 2007; 1.

31. Macedo REF. Utilização de culturas lácticas probióticas no processamento de produto cárneo fermentado. Tese apresentada ao Programa de Pós-Graduação em Tecnologia de Alimentos. Universidade Federal do Paraná, Curitiba, 2005.

32. Prpich NZP, Castro MP, Cayré ME, Garro OA, Vignolo GM. Indigenous Starter Cultures to Improve Quality of Artisanal Dry Fermented Sausages from Chaco (Argentina). Int. J. Food Sci. 2015; 2015: 1-9.

33. Dalla Santa O R. Avaliação da qualidade de salames artesanais e seleção de culturas starter para a produção de salame tipo italiano (Tese de doutorado). Universidade Federal do Paraná, Curitiba, 2008.

34. Aguilera JM, Chirife J. Combined methods for the preservation of foods in Latin America and the CYTEDD Project. J. Food Eng. 1994; 22: 433-444.

35. Flores J, Bermell S. Propriedades funcionales de las proteínas miofibrilares: capacidad de retención de agua. Rev. Agroqui. Tecnol. Aliment. 1984; 24(2): 151-158.

36. Ibañez C, Quintanilla L, Cid C, Astiasarán I, Bello J. Dry fermented sausages elaborated with Lactobacillus plantarum - Staphylococcus carnosus. Part II: Effect of partial replacement of $\mathrm{NaCl}$ with $\mathrm{KCl}$ on the proteolytic and in solubilization processes. Meat Sci. 1997; 46: 277-284.

37. Zanardi E, Ghidini S, Battaglia A, Chizzolini R.Lipolysis and lipid oxidation in fermented sausages 
depending on different processing conditions and different antioxidants. Meat Sci, 2004; 66: 415-423.

38. Santa ORD, Macedo REF, Santa HSD, Zanette, CM, Freitas RJS, Terra NN. Use of starter cultures isolated from native microbiota of artisanal sausage in the production of Italian sausage. Food Sci. Technol. 2014; 34: 780-786.

39. Bozkurt H, Erkmen O. Effects of starter culture and additives on the quality of Turkish style sausage (sucuk). Meat Sci. 2002; 61: 149-156.

40. Yang HS, Choi SG, Jeon JT, Park GB, Joo ST. Textural and sensory properties of low fat pork sausages with added hydrated oatmeal and tofu as texture-modifying agents. Meat Sci. 2007; 75(2): 283-289.

41. Cenci-Goga BT, Ranucci D, Miraglia D, Cioffi A. Use of starter cultures of dairy origin in the production of Salame nostrano, an Italian dry-cured sausage. Meat Sci. 2008; 78(4): 381-390.

42. Soyer A, Ertas AH, Üzümcüoglu Ü. Effect of processing conditions on the quality of naturally fermented Turkish sausages (sucukus). Meat Sci. 2005; 69: 135-141.

43. Rantsiou K, Cocolin L. New developments in the study of the microbiota of naturally fermented sausages as determined by molecular methods: A review. Int. J. Food Microbiol. 2006; 108: 255-267. 